\title{
SMASIS2016-9183
}

\section{ENGINEERING DESIGN TOOLS FOR SHAPE MEMORY ALLOY ACTUATORS: CASMART COLLABORATIVE BEST PRACTICES AND CASE STUDIES}

\author{
Robert W. Wheeler \\ A\&M University \\ College Station, TX, USA \\ Xiujie Gao \\ General Motors R\&D \\ Warren, MI, USA
}

Department of Aerospace Engineering, Texas

\author{
Othmane Benafan \\ Structures and Materials Division, NASA Glenn \\ Research Center \\ Cleveland, $\mathrm{OH}$, USA
}

\author{
Frederick T. Calkins \\ The Boeing Company \\ Seattle, WA, USA
}

\author{
Zahra Ghanbari \\ Department of Metallurgical \& \\ Materials Engineering, Colorado \\ School of Mines \\ Golden, CO, USA \\ Andrew Petersen \\ Department of Electrical \\ Engineering \& Computer Science, \\ Colorado School of Mines \\ Golden, CO, USA \\ Travis L. Turner \\ Structural Acoustics Branch, \\ NASA Langley Research Center \\ Hampton, VA, USA
}

Dimitris Lagoudas

Department of Aerospace

Engineering, Texas A\&M

University

College Station, TX, USA

Aaron P. Stebner

Department of Mechanical

Engineering, Colorado School of

Mines

Golden, CO, USA

\begin{abstract}
The primary goal of the Consortium for the Advancement of Shape Memory Alloy Research and Technology (CASMART) is to enable the design of revolutionary applications based on shape memory alloy (SMA) technology. In order to help realize this goal and reduce the development time and required experience for the fabrication of SMA actuation systems, several modeling tools have been developed for common actuator types and are discussed herein along with case studies, which highlight the capabilities and limitations of these tools. Due to their ability to sustain high stresses and recover large deformations, SMAs have many potential applications as reliable, lightweight, solid-state actuators. Their advantage over classical actuators can also be further improved when the actuator geometry is modified to fit the specific application. In this paper, three common actuator designs are studied: wires, which are lightweight, low-profile, and easily implemented; springs, which offer actuation strokes upwards of $200 \%$ at reduced mechanical loads; and torque tubes, which can provide large actuation forces in small volumes and
\end{abstract}

develop a repeatable zero-load actuation response (known as the two-way shape memory effect). The modeling frameworks, which have been implemented in the design tools, are developed for each of these frequently used SMA actuator types. In order to demonstrate the versatility and flexibility of the presented design tools, as well as validate their modeling framework, several design challenges were completed. These case studies include the design and development of an active hinge for the deployment of a solar array or foldable space structure, an adaptive solar array deployment and positioning system, a passive air temperature controller for the regulation of flow temperatures inside of a jet engine, and a redesign of the Corvette active hatch, which allows for pressure equalization of the car interior. For each of the presented case studies, a prototype or proof-of-concept was fabricated and the experimental results and lessons learned are discussed. This analysis presents a collection of CASMART collaborative best practices in order to allow readers to utilize the available design tools and understand their modeling principles. These design tools, which are based on 
engineering models, can provide first-order optimal designs and are a basic and efficient method for either demonstrating design feasibility or refining design parameters. Although the design and integration of an SMA-based actuation system always requires application- and environment-specific engineering considerations, common modeling tools can significantly reduce the investment required for actuation system development and provide valuable engineering insight.

Keywords: CASMART; shape memory alloy (SMA); design tools; actuator design; solid state actuators

\section{INTRODUCTION}

Shape memory alloys (SMAs) offer a revolutionary and innovative capability which can provide potential solutions to many of today's engineering problems. Specifically, SMA actuators are an enabling technology due to their compact form, high energy densities, and multifunctional capabilities. However, transitioning from a useful material to a functional component/system requires engineering design tools that provide a balance between material science and engineering practices to guide the users (including non-experts) through an iterative design approach. Moreover, these tools need to be adequately formulated to account for material properties, boundary conditions, stroke/power requirements, and other SMA actuation attributes to inform the choice for an optimum design solution. Depending on the design method, the tools could be first order calculations, engineering models, or even more sophisticated constitutive approaches [1-7].

The unique properties of SMA materials for actuation has made them attractive options for solving engineering problems. Numerous applications of SMA actuators are commercially available and documented in literature; this includes applications in fields as diverse as medical, aerospace, automotive, consumer products, safety products, oil and gas, and robotics. Examples of applications that have explored numerous SMA actuation forms and a range of requirements of load, stroke, rate, life cycle, and material properties can be found in the references [8-15]. One common limitation on the exploitation of SMA actuators across these fields has been the relative lack of basic and reliable design tools. This is a limitation that the Consortium for the Advancement of Shape Memory Alloy Research and Technology (CASMART) has attempted to remedy through collaborative research and publications.

CASMART is a group of industry, academic, and government organizations which seeks to promote the growth and adoption of SMA actuation technologies by achieving new understanding of the materials, fostering dissemination of technical knowledge, and facilitating application of that knowledge. CASMART has previously reported on critical aspects of SMA actuator system design [1], including numerical modeling of SMA actuators. Engineering models are of particular interest since they can be readily developed from empirical data and provide a very simple and efficient means to refine the design parameters. To date, there are several resources that provide useful design tools for a specific SMA actuator form [1]. Frequently these tools are described more generally and examples or validation of the approaches are not available. In an effort to promote the evaluation and comparison of actuation forms and to evaluate design tools, the CASMART Design Working Group initiated a student design challenge in 2015. The challenge focused on developing and using SMA actuator design tools to facilitate solutions to three proposed problems: a deployable solar array, an automotive vent, and jet engine thermal management.

Six teams of graduate and undergraduate students from Colorado School of Mines, Texas A\&M University, and University of North Texas competed in the design challenge. The CASMART Design Working group provided details on the three potential applications and subject matter experts to act as mentors to the teams. The teams chose an application and went through a design, build, and test cycle. The teams worked with their mentors to research, develop, and use a design tool specific to the actuation element form they chose. The SMA element forms considered by the teams included tubes (rotary), wire (linear), helical coil (linear), and plate (bending). Five teams completed the challenge by demonstrating their hardware solutions at a special session at the Smart Materials, Adaptive Structures, and Intelligent Systems Conference (SMASIS) 2015 in Colorado Springs, CO. The design freedom enabled by considering a variety of SMA element forms led directly to creative solutions offered by the teams.

The tools described herein were developed, refined, and implemented for the 2015 Design Challenge. Tools are now available for the most frequently used SMA actuator types: wire, spring, torque tube, and plate. The tools account for practical actuator parameters implemented in a graphical user interface (GUI) where users can quickly change inputs and iterate through the design cycle. One of the intriguing elements of SMA actuator design is the selection of the actuator type. The tools presented here enable a designer to compare actuator types in order to determine the best design that meets the given requirements. These tools are first order approximations that capture the macroscopic effect of forward and reverse phase change of various SMA elements that leads to the desired shape change and effective actuation. As expected, the models are quite similar in the handling of the transformation process but differ due to the employed actuation strains and geometric constraints. It is acknowledged at this point that the tools developed here are first order approximation and for the most part do not represent the complex inelastic phase transformation and nonlinear nature of the SMA response. As such, for more advanced SMA modeling needs, readers are referred to other three-dimensional constitutive approaches such as Stebner et al. [5], Saleeb et al. [6], and Lagoudas et al. [7]. Implementation of these tools is validated through several case studies that highlight their practicality and limitations.

The case studies included in this paper are: reconfigurable SMA-Based solar array deployment mechanism using SMA torque tube (Section 3.1), spring based Sunshade solar (Section 3.2), Passive gas turbine core airflow temperature controller 
(Section 3.3), and wire-based Corvette active hatch redesign (Section 3.4).

\section{SMA DESIGN TOOLS}

\subsection{Wire Actuators}

This is a simple SMA wire actuator design tool using a Martensite and an Austenite design curve with a linear bias spring. The design curves can be generated in a few different ways $[3,4]$. The most common approach is a pair of isothermal pull tests, one at high temperature giving the nearly linear forcedisplacement relationship for the Austenite phase. The other is at low temperature for the Martensite phase. The second method is a less common, more time consuming cyclic method that produces data only at discrete constant force levels, but is more relevant and accurate for shape memory effect. A third method that Dynalloy uses is to plot the increase and later decrease in length of wires as they are subjected to increasing and later decreasing forces at constant temperatures. These isothermal tests show the relationship between a hot wire (above its contraction transition temperature) and a cold wire (below its relaxation transition temperature). More sophisticated design tools also exist; see the GM sponsored work at University of Michigan on Conglomerate Stabilization Curve Design Method [16].

The tool inputs such design curves from a tab delimited text file with four columns: Martensite Strain, Martensite Stress (in MPa), Austenite Strain, and Austenite Stress. Currently, the input file name is forced to be "Cycle1.txt." The file's content can be replaced with custom curves. The tool cannot calculate before curves are loaded. In addition, the tool checks the input curves and ensures at least a portion of both the Martensite and Austenite design curves is in the first quadrant. Figure 1 shows the MATLAB GUI interface and Figure 2 shows a solution message.

The Wire Design Tool populates all input parameters with their default value before allowing the user to interactively input each parameter one at a time. These parameters describe the wire and the system. The tool performs a check of each parameter and resets it to the default value if the input is invalid. Every time a parameter is changed, all previous calculation results (if any) are erased and both graphs are updated accordingly. These graphs show only the austenite and martensite curves and the vertical cold stop line. No attempt to calculate a solution is made until the user presses the Calculate button. A solution message will be shown along with updated solution in the graph. The red star is for the target position and blue star is for the intercept of the martensite curve and the bias spring curve. The wire volume and maximum stress will also be updated below the inputs. The user can also press the Output button to output the solution to a text file. Otherwise, a warning or error message will be displayed if no solution can be found. These input parameters, categorized as pertaining to either the Wire or System along with the description and range for the input, the default value and the symbol, are summarized in Table 1. Here, AmbientTemperature, HeatingCurrent and CoolToTemperature are treated as input for wire parameters although they can treated as System input parameters.

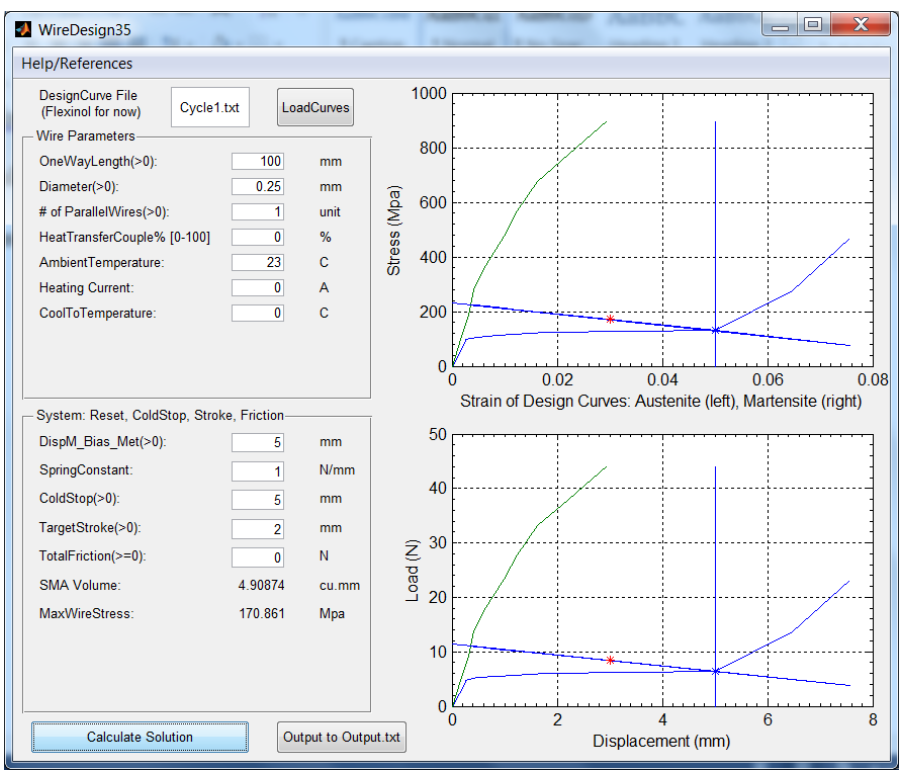

Figure 1: The MATLAB GUI interface. Each figure includes the Austenite curve (left), the Martensite curve (right), the bias load (horizontal), and the vertical cold stop (at $5 \%$ and $5 \mathrm{~mm}$ in this case).

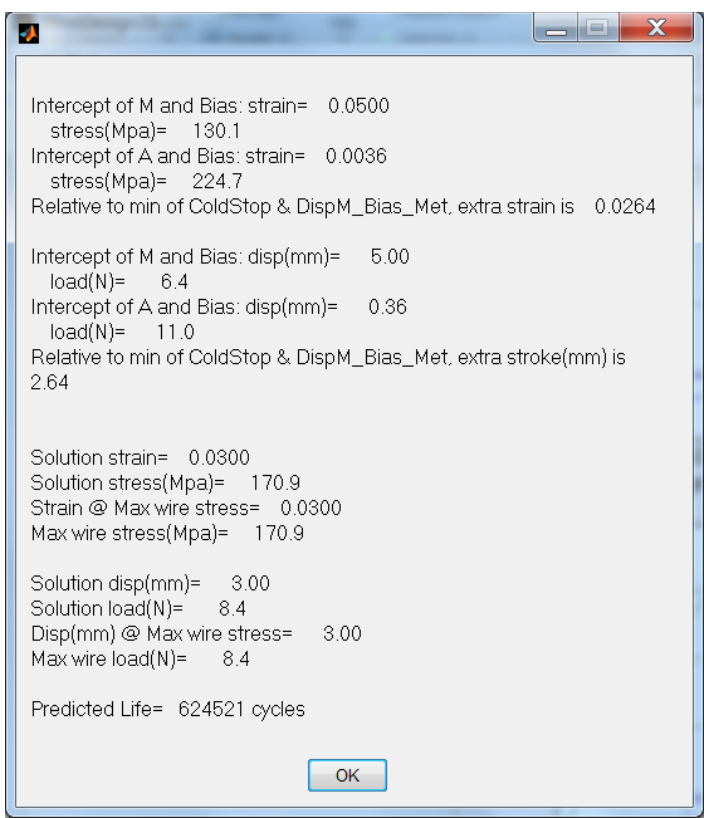

Figure 2: Example output or solution message of the wire design tool 
Table 1: Required Input Parameters for Wire Design Tool

\begin{tabular}{|c|c|c|c|c|c|}
\hline Name & Unit & Type & Description and Range for input & Reset value & Symbol \\
\hline OneWayLength & $\mathrm{mm}$ & Input: Wire & $>0$, length of one or more wires mechanically in series & 100 & $\mathrm{~L}$ \\
\hline Diameter & $\mathrm{mm}$ & Input: Wire & $>0$, wire diameter & 0.25 & $d$ \\
\hline \# of ParallelWires & unit & Input: Wire & $>0$, \# of mechanically parallel wires & 1 & $\mathrm{n}$ \\
\hline HeatTransferCouple & $\%$ & Input: Wire & $\begin{array}{l}{[0,100], 0 \text { : individual heat transfer as others do not exist, }} \\
100: \text { all parallel wires as one wire in heat transfer calculation. }\end{array}$ & 0 & c \\
\hline AmbientTemperature & $\mathrm{C}$ & Input: Wire & Must be a number & 23 & Tamb \\
\hline HeatingCurrent & $A$ & Input: Wire & $>=0 ; 0$ for no heat transfer calculation & 0 & A \\
\hline CoolToTemperature & $\mathrm{C}$ & Input: Wire & Must be a number & $T a m b+5$ & Tcool \\
\hline DispM_Bias_Met & $\mathrm{mm}$ & Input: System & $\begin{array}{l}>0 \text {, Displacement where Martensite Curve \& Linear Bias } \\
\text { Spring intercepts }\end{array}$ & $5 \%$ of $L$ & Dint \\
\hline SpringConstant & $\mathrm{N} / \mathrm{mm}$ & Input: System & Must be a number & 1 & $\mathrm{k}$ \\
\hline ColdStop & $\mathrm{mm}$ & Input: System & Wire stop position at cold & Dint & Dcold \\
\hline TargetStroke & $\mathrm{mm}$ & Input: System & $\begin{array}{l}>0 \text {, Total motion amount to the left of minimum of Dint or } \\
\text { Dcold }\end{array}$ & $2 \%$ of $L$ & $\mathrm{D}$ \\
\hline TotalFriction & $\mathrm{N}$ & Input: System & $>=0$ & 0 & f \\
\hline Volume & $\mathrm{mm}^{\wedge} 3$ & Output & & & V \\
\hline MaxWireStress & $\mathrm{MPa}$ & Output & Maximum stress the wire experiences & & Smax \\
\hline
\end{tabular}

revents the cold (martensite) SMA from stretched further to the right. DispM_Bias_Met is the intercept of the Martensite design curve and the Bias line. This is the starting point upon which the SMA will shrink upon heating and go to the left along the Bias line. The Bias spring constant is typically positive.

A simple fatigue Life prediction is based on the hot wire stress, the amount of motion specified by the TargetStroke and the ColdStop position. For a ColdStop position that is larger than DispM_Bias_Met, it has an adverse impact on the fatigue life. Only the first 0.02 in terms of strain, (ColdStopDispM_Bias_Met)/Length, is considered.

\subsection{SPRING ACTUATORS}

Similar to the wire design tool, the spring program collects input parameters which describe the material and actuator application, and outputs austenite and martensite positions and loads. These input parameters, which can be categorized as pertaining to either the spring geometry, the actuator application, or the intrinsic materials properties, are summarized in Table 2:

These material properties are generally available in literature and/or from actuator wire vendors. A discussion of methods utilized for obtaining these material properties can be found in the following references [16-18]. Once the design tool receives the necessary inputs, a series of intermediate calculations are performed prior to the generation of the design space and solution.

The spring index, $C$, is calculated in equation 1 and the number of active coils, $N_{a}$, is calculated in equation 2 . The various values the end condition, $E C$, can take are shown in Figure 3.
The pitch, $p$, and pitch angle, $\alpha$, are calculated via Equations 3 and 4 , respectively. These geometric properties can be seen schematically in Figure 4.

$$
\mathrm{p}=\frac{L_{o}}{N_{a}}
$$
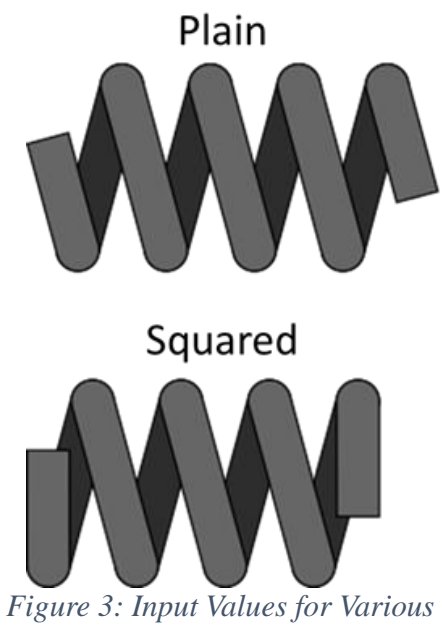

Squared

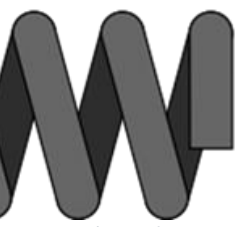

$$
\alpha=\tan ^{-1}\left(\frac{p}{\pi \cdot D}\right)
$$

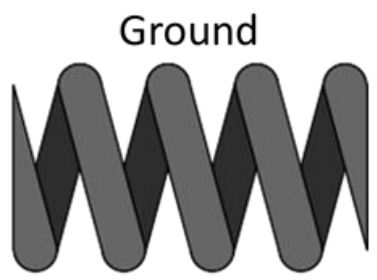

Squared and Grounc

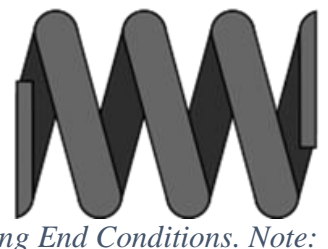

inputs for EC represent number of inactive coils; 


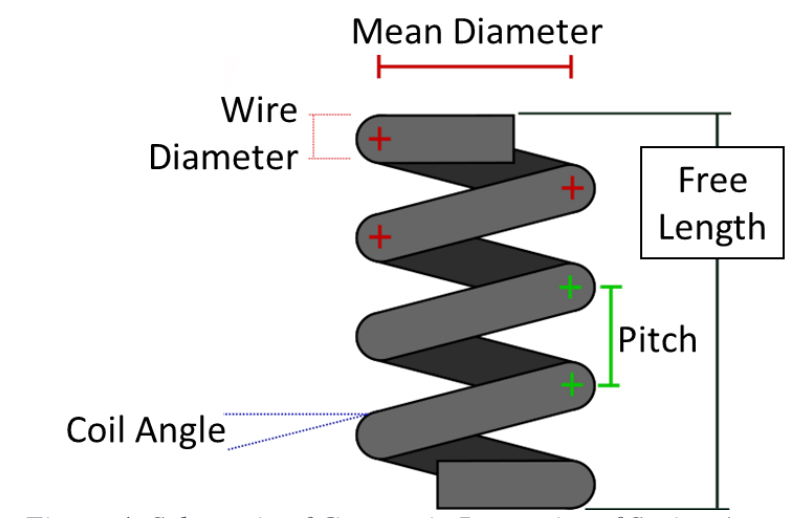

Figure 4: Schematic of Geometric Properties of Spring Actuator

Table 2: Required Input Parameters for Spring Design Tool

\begin{tabular}{|c|c|c|c|}
\hline Input Value & Input Unit & Input Type & Symbol \\
\hline $\begin{array}{c}\text { Wire } \\
\text { Diameter }\end{array}$ & $\mathrm{mm}$ & Spring Geometry & $d$ \\
\hline $\begin{array}{c}\text { Coil } \\
\text { Diameter }\end{array}$ & $\mathrm{mm}$ & Spring Geometry & $D$ \\
\hline Free Length & $\mathrm{mm}$ & Spring Geometry & $L_{o}$ \\
\hline $\begin{array}{l}\text { Number of } \\
\text { Coils }\end{array}$ & - & Spring Geometry & $N_{t}$ \\
\hline $\begin{array}{c}\text { End } \\
\text { Condition }\end{array}$ & - & Spring Geometry & $E C$ \\
\hline $\begin{array}{l}\text { Shear } \\
\text { Modulus }\end{array}$ & GPa & Material Property & $G_{A}, G_{M}$ \\
\hline $\begin{array}{l}\text { Young's } \\
\text { Modulus }\end{array}$ & GPa & Material Property & $E_{A}, E_{M}$ \\
\hline $\begin{array}{c}\text { Poisson's } \\
\text { Ratio }\end{array}$ & - & Material Property & $v_{A}, v_{M}$ \\
\hline Density & $\mathrm{g} / \mathrm{cm}^{3}$ & Material Property & $\rho$ \\
\hline $\begin{array}{l}\text { Applied } \\
\text { Force }\end{array}$ & $\mathrm{N}$ & Actuator Property & $F$ \\
\hline $\begin{array}{c}\text { Load } \\
\text { Evolution }\end{array}$ & $\mathrm{N} / \mathrm{mm}$ & Actuator Property & $\Delta F$ \\
\hline Cold Position & $\mathrm{mm}$ & Actuator Property & $x_{M}$ \\
\hline
\end{tabular}

Once the intermediate calculations are completed, the following values are determined and generated in the design tool GUI and output text file. The overall length of the wire, $L_{W}$, and actuator mass, $m$, are calculated through Equations 5 and 6, respectively:

$$
m=\rho \cdot L_{w}\left(\frac{\pi \cdot d^{2}}{4}\right)(5) \quad L_{W}=\pi \cdot D\left(\frac{N_{a}}{\cos (\alpha)}+E C\right)
$$

The length of the spring actuator while fully compressed is determined in Equation 7:

\footnotetext{
${ }^{1}$ More information regarding the stiffness calculations utilized in the model can be found in [18]
}

$$
L_{\text {solid }}=d \cdot\left(N_{a}+E C\right)
$$

The values of the stiffness in austenite and martensite are calculated through the following reduced form ${ }^{1}$ :

$$
k_{A}=\left(\frac{G_{A} \cdot d^{4}}{8 \cdot N_{a} \cdot D^{3}}\right) \quad(8) \quad k_{M}=\left(\frac{G_{M} \cdot d^{4}}{8 \cdot N_{a} \cdot D^{3}}\right)
$$

From the stiffness values, a Force-Deflection design space, such as the one shown in Figure 5, is generated for the input parameters. In addition to the figure, the spring constants for each estimation technique and the intermediate calculations are reported.

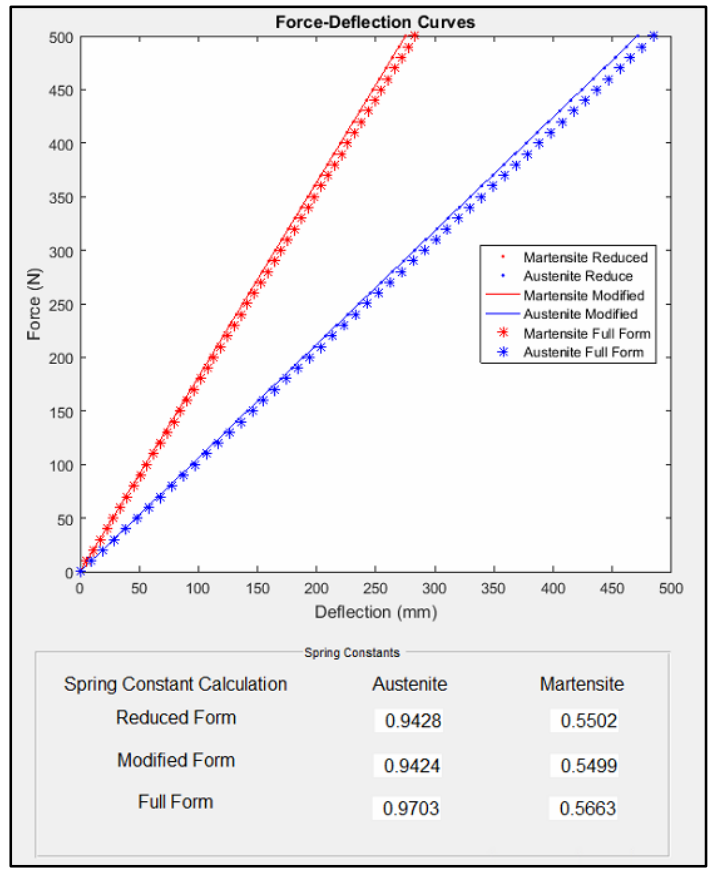

Figure 5: Design Space and Graphical Output from Spring Design Tool

From this figure, a spring actuator can be designed either by selecting a load and determining the actuation stroke or vice versa.

\subsection{TORQUE TUBE ACTUATORS}

Due to the complexity inherent to designing a torque tube actuator and the increased procurement time/development cost, the torque tube selection tool chooses an optimal design based on the set of constraints on the system, material properties, and cost function it takes as input parameters. Similar to the spring 
module, the torque tube selection tool requires material properties as inputs; however, unlike the spring and wire tools, it implements a simple optimization through a design of experiments (DOE) technique. While this increases the computation time of the design tool, it allows the user to create a design space and possesses the ability to find optimal solutions based on power, time, environmental, and mechanical restrictions or conditions. The SMA model utilized in this module of the design tool is based on the $1 \mathrm{D}$ reduction of the SMA constitutive model proposed by Lagoudas et. al [7]. The required input parameters are listed in Table 3. design iteration. The corresponding temperature loss, $T_{\text {lost }}$, is shown in Equation 12. The temperature gained, due to power input from the system, is shown in Equation 13.

$$
\begin{gathered}
E_{\text {lost }}=T_{\text {sma }}^{4} * \sigma_{\text {bolt }} * \Delta t * A_{O} \\
T_{\text {lost }}=\frac{T_{s m a}^{4} * \sigma_{\text {bolt }} * \Delta t * A_{O}}{C_{s m a} m_{s m a}} \\
T_{\text {gained }}=\frac{P * \Delta t}{m_{s m a} * c_{s m a}}
\end{gathered}
$$

Once the temperature is determined from iterating the thermal

\begin{tabular}{|c|c|c|c|c|}
\hline Input Value & Input Unit & Input Type & Value Type & Symbol \\
\hline Tube Thickness & $\mathrm{mm}$ & Tube Geometry & Range & $t_{\min }, t_{\max }$ \\
\hline Tube Radius & $\mathrm{mm}$ & Tube Geometry & Range & $R_{\min }, R_{\max }$ \\
\hline Tube Length & $\mathrm{mm}$ & Tube Geometry & Single & $L$ \\
\hline Available Power & W & System & Range & $P_{\min }, P_{\max }$ \\
\hline Heating Time & $\mathrm{s}$ & System & Range & time $_{\text {heat }}$ \\
\hline Cooling Time & $\mathrm{s}$ & System & Range & time $_{\text {cool }}$ \\
\hline Applied Torque & $N \cdot m$ & System & Single & Torque $_{a p p}$ \\
\hline Load Increase & $(\mathrm{N} \cdot \mathrm{m}) /$ degree & System & Single & $\Delta$ Torque \\
\hline Actuation Rotation Angle & degree & System & Single & $\varphi$ \\
\hline Shear Moduli & GPa & Material Property & Single & $G_{A}, G_{M}$ \\
\hline Max Shear Stress & $\mathrm{MPa}$ & Material Property & Single & $\tau_{\max }$ \\
\hline Max Shear Strain & - & Material Property & Single & $\gamma_{\max }$ \\
\hline Poisson's Ratios & - & Material Property & Single & $v_{A}, v_{M}$ \\
\hline Density & $\mathrm{g} / \mathrm{cm} 3$ & Material Property & Single & $\rho$ \\
\hline Thermal Emissivity & - & Thermal Property & Single & $e$ \\
\hline Convection Coefficient & $\mathrm{W} / \mathrm{m}^{2}$ & Thermal Property & Single & \\
\hline Grey Body Temperature & $\mathrm{K}$ & Thermal Property & Single & $T_{e}$ \\
\hline Specific Heat & $\mathrm{J} / \mathrm{g}$ & Thermal Property & Single & $c$ \\
\hline Thermal Time Step & s & Thermal Property & Single & $\Delta t$ \\
\hline Cost Function & - & DOE Setting & Function & - \\
\hline Resolution & $\%$ & DOE Setting & Single & - \\
\hline
\end{tabular}
calculation, the martensitic volume fraction, $\xi$ or MVF, is

Table 3: Input Parameters for Torque Tube Design Tool

While power considerations are less important for wire or spring actuators (relative to bulk actuators), they can have large impacts on torque tube actuator designs as restrictions on available power or actuation time may severely limit the design space. In order to take heating time and power into account, simplified convection and grey body radiation are implemented in an iterative thermal solver:

$$
T_{\text {sma }}(i+1)=T_{\text {sma }}(i)+T_{\text {gained }}(i)-T_{\text {lost }}(i)
$$

where the iteration rate is determined by the thermal time step $\Delta t$. The energy lost due to grey body radiation, $E_{\text {lost }}$, is shown below in Equation 11, where $\sigma_{\text {bolt }}$ is the Boltzmann constant and $A_{O}$ is the calculated surface area for the current torque tube determined through Equations 14 (cooling) and 15 (heating), which use the stress from the previous time step. Given the hysteretic behavior of SMAs, separate equations must be utilized.

$$
\xi=\left\{\begin{array}{c}
0, \quad T \geq M_{s}^{\sigma} \\
\frac{M_{s}+\frac{\tau}{C^{M}}-T}{M_{s}-M_{f}}, \quad M_{f}^{\sigma}<T<M_{s}^{\sigma} \\
1, \quad T \leq M_{f}^{\sigma}
\end{array}\right.
$$




$$
\xi=\left\{\begin{array}{c}
1, T \leq A_{s}^{\sigma} \\
\frac{A_{f}+\frac{\tau}{C^{A}}-T}{A_{f}-A_{s}}, A_{s}^{\sigma}<T<A_{f}^{\sigma} \\
0, \quad T \geq A_{f}^{\sigma}
\end{array}\right.
$$

This internal state variable also describes the transformation strain, Equation 16.

$$
\gamma^{t}=\xi * H^{c u r}
$$

where $H^{\text {cur }}$ is defined as a function of the applied stress:

(17) $H^{\text {cur }}(\tau)=$
$=\left\{\begin{array}{c}H^{T W S M E} \\ H^{T W S M E}+\left(H^{\text {sat }}-H^{T W S M E}\right)\left(1-e^{-k\left(\tau-\tau^{c r i t}\right)}\right), \quad \tau \leq \tau^{\text {crit }}\end{array}\right.$

As this transformation is taking place, the stiffness of the material is also evolving and is described in Equation 18:

$$
E=E_{A}+\xi\left(E_{M}-E_{A}\right)
$$

Finally, the angle of rotation, $\varphi$, is determined by:

$$
\varphi=\frac{\gamma L}{R}
$$

where the total strain, $\gamma$, has an elastic and transformation component:

$$
\gamma=\gamma^{t}+\gamma^{e} \quad(20) \quad \gamma^{e}=\tau \frac{2(1+v)}{E}
$$

The iterative solution method is shown schematically in Figure 6 for a single step in the design optimization. Once the input parameters are collected, either from the initial values given by the user or the previous iteration, a heating increment is performed and the module checks for full reverse transformation (heating). Additional heating increments are performed until the SMA has either fully transformed or the heating time limit has been reached. A similar process is then completed for the cooling stage or forward transformation. Once the calculations are complete for the thermal cycle, the new solution is checked against the input restrictions (e.g. power consumption or actuation rotation angle) and then compared to the previous optimal solution.

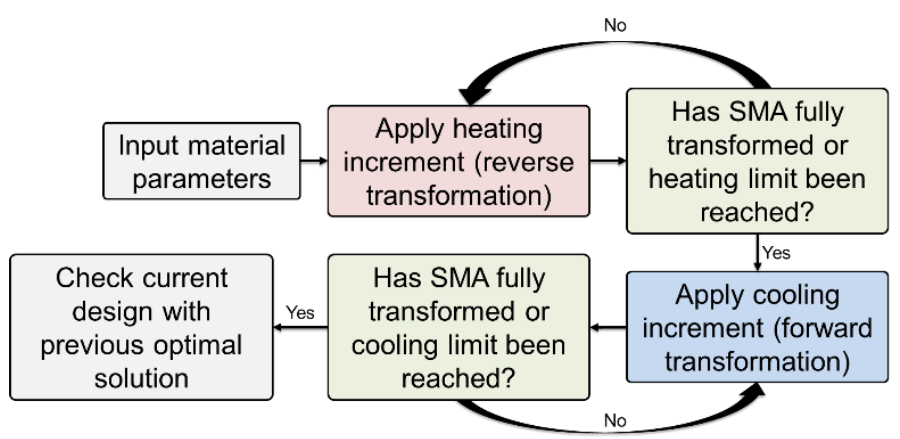

Figure 6: Torque Tube Design Module Solution Algorithm

Once the optimization is complete, the design parameters shown in Table 4 are written to the output text file and plots of shear stress and strain vs. temperature are generated. Examples of these plots are shown in Figure 7.

Table 4: Torque Tube Selection Tool Outputs

Input Value

Output Unit

$\begin{array}{lr}\text { Torque Tube Length } & \mathrm{mm} \\ \text { Torque Tube Radius } & \mathrm{mm} \\ \text { Torque Tube Thickness } & \mathrm{mm} \\ \text { Torque Tube Mass } & \mathrm{g} \\ \text { Critical Strain - Temperature Coordinates } & \%, \mathrm{~K} \\ \text { Max Shear Stress } & \mathrm{MPa} \\ \text { Max Shear Strain } & \% \\ \text { Transformation Temperatures } & \mathrm{K} \\ \text { Actuation Rotation } & \text { degree }\end{array}$

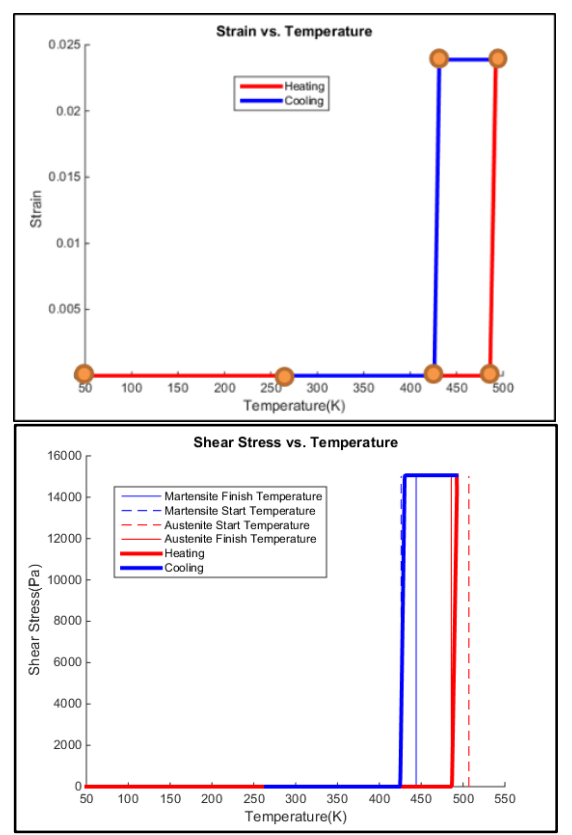

Figure 7: Plots Generated for Optimal Solution in Torque Tube Module. Top: Shear Strain vs. Temperature; Bottom: Shear Stress vs. Temperature. 
In order to validate the modeling predictions, several experiments were carried out and can be found in the first case study.

\section{CASE STUDIES}

In order to evaluate the capabilities, accuracy, and flexibility of the design tool, three design challenges were proposed by CASMART and the design tool modules outlined in the previous section were provided to the teams. The case studies reported in the following sections are comprised of results and lessonslearned from the design teams who successfully completed the challenge and developed an optimized design and functioning proof-of-concept or prototype.

The design challenges included: the development of a solar-array deployment device (Figure 8a), a redesign of the Corvette Active Hatch Vent (8c), and a passive gas turbine core airflow temperature controller (8b).

\subsection{RECONFIGURABLE SMA-BASED SOLAR ARRAY DEPLOYMENT MECHANISM}

One of the motivating factors behind developing the CASMART SMA actuator design tool was to demonstrate the ability of SMA actuators to adapt to various engineering challenges. This adaptability is captured in the design of a reconfigurable SMABased solar array deployment mechanism as it takes advantage of both spring and torque actuators, which provide large actuation strokes and reliable TWSME, respectively.
In the completed design and functioning prototype, shown in Figure 9, the torque tube system provides the necessary rotation to open the panels while the SMA spring actuates to open a latch which, when actuated, allows the system to freely deploy/retract or, when cold, keeps the system in a deployed configuration. This allows the panels to rest in the open or closed configuration without necessitating continuous heating and power consumption.

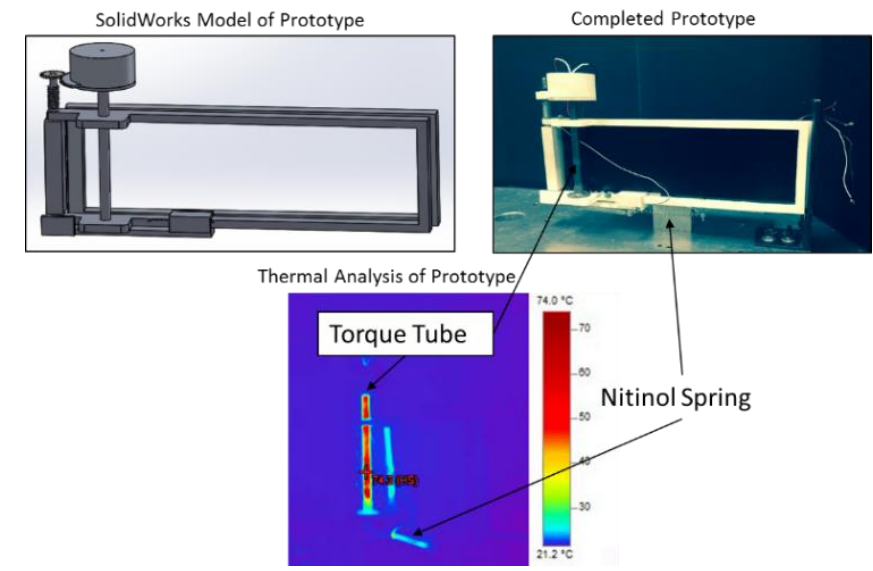

Figure 9: Completed design of the active hinge system for solar array deployment. From top left $(\mathrm{CW})$ : SolidWorks drawing of prototype used for $3 D$ printing of parts; completed prototype with Nitinol actuators; Thermal analysis showing simultaneous heating in spring and torque tube actuators.

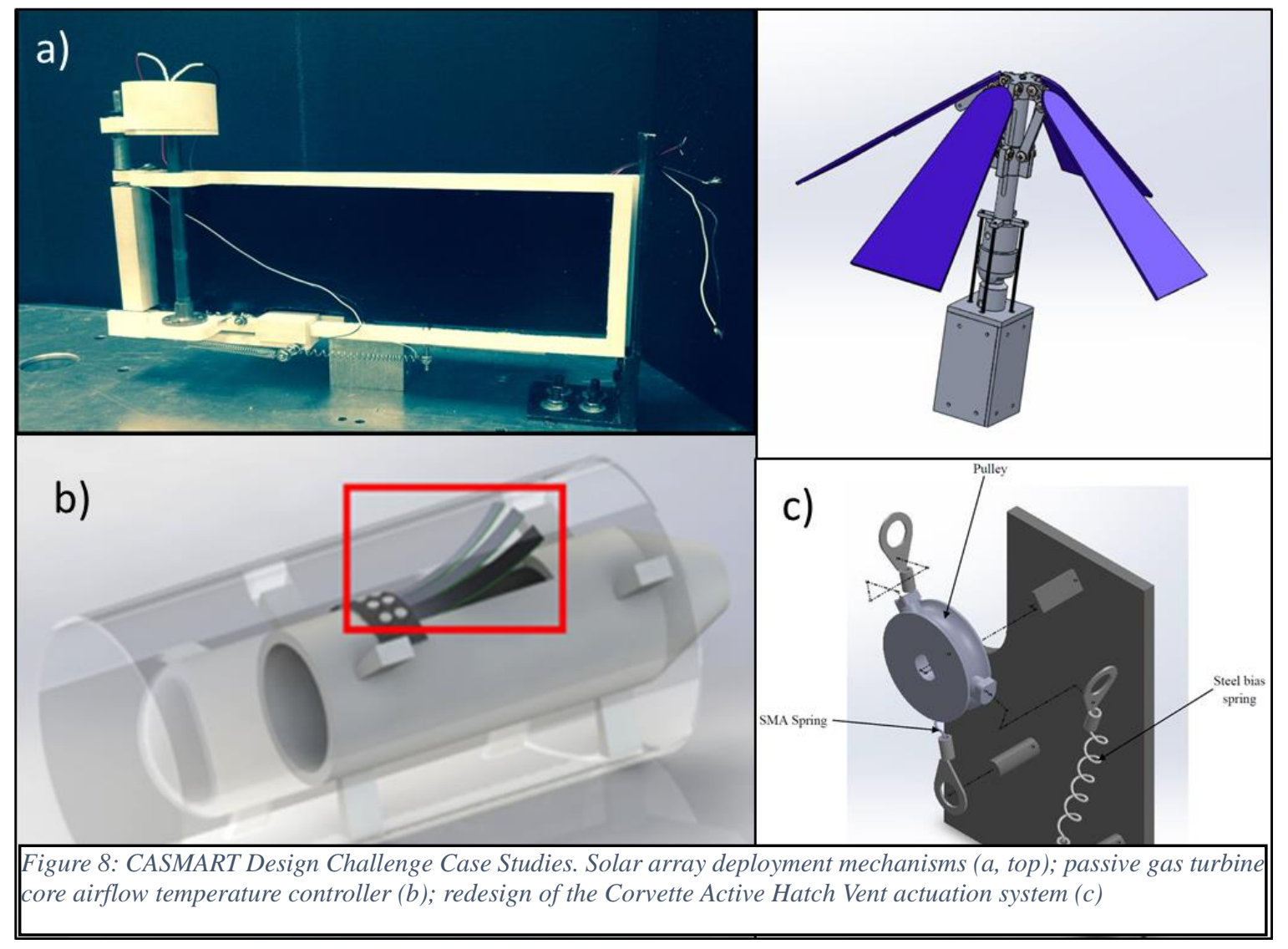




\subsubsection{Design Requirements}

Due to the limited carrying capacity of existing launch vehicles and their strict geometrical constraints, SMAs further prove useful as a result of their flexibility and actuation energy density [19]. As a result of these advantageous characteristics, SMA actuators have been considered in the Solar Sail Project as the mechanism to launch deployable booms [20]. The use of SMAs provides multiple improvements such as a reduction in mass, fulfillment of minimum bending stiffness requirement and geometrical constraints, independence from power sources, and timely deployment (approximately 10 seconds) [21]. SMAs have been utilized in satellite antennas in the form of nitinol plates and rods, the Hubble Space Telescope's solar panel for the offloading system, NASA's Mars Pathfinder Rover to open and rotate the glass dust cover of solar cells, lightweight flexible solar arrays as a result of thin SMA strips as hinges, and deployable shrouds to protect the equipment or personnel of a space station [22].

The goal of this study was to design and analyze a small-scale (1U Cubesat) SMA-based deployment device for a solar array. The design created considers a failsafe deployment mode where the system would fail to a deployed state, allowing for the collection of solar energy. The deployment system is actively controlled; however, it is also able to maintain the panels in a closed position for launch and in a deployed state for continuous usage. The deployment system was designed to operate at an altitude of $400-600 \mathrm{~km}$ with a minimum beta angle of $75^{\circ}$.

The size of the SMA-based solar array system deployment device was based on a $1 \mathrm{U}$ microsat scale, but was designed to be scalable to multiple array systems [9]. For launch, the design fits within a volumetric footprint that is $46 \mathrm{~cm} \times 16 \mathrm{~cm}$ $\mathrm{x} 10 \mathrm{~cm}$. A vibration analysis was performed in SolidWorks to ensure that the design would be able to withstand the vibrations from launch.

In the deployed state, there are two panels housed in the frame, which measures $37 \mathrm{~cm}$ long and $14.5 \mathrm{~cm}$ wide for each panel. The frame that holds the panels is aluminum, and the solar panels are standard COTS solar panels with an assumed efficiency of $30 \%$. The frame serves as a housing for the solar panels, and as a mounting point to the satellite. The height of the frame edge is $1 \mathrm{~cm}$ and the width is $0.6 \mathrm{~cm}$. A stepper motor is attached to the fixed end allowing reorientation of the panels for optimum albedo angles.

\subsubsection{Optimized Design}

The goal of this case study was to design and analyze a smallscale SMA-based deployment device for a solar array. The design challenge consisted of volumetric constraints $(46 \mathrm{~cm} \mathrm{x}$ $16 \mathrm{~cm} \times 10 \mathrm{~cm})$ on the stowed geometry, an operational environment of an altitude of $400-600 \mathrm{~km}$ with a minimum beta angle of $75^{\circ}$, launch vibrations up to $0.18 \mathrm{~g}^{2} / \mathrm{Hz}$, power system requirements of $50 \mathrm{~W}$ for 60seconds, energy harvesting requirements which would exceed the deployment cost, mass reduction when compared to conventional actuators, a failsafe system to ensure deployment, and a reorientation system for optimal collection of solar energy.

The actuator used in this design is a nickel titanium hafnium torque tube. An actuation cycle of this torque tube was simulated and is shown in Figure 10. The temperature of the material was increased starting from $50 \mathrm{~K}$, which was selected to represent a worst-case scenario of the lowest temperature that the torque tube could reach in low Earth orbit. From this point, the simulation heats the torque tube conductively to a temperature above austenite start. Figure 10 shows how the torque tube's shear stress decreases during a partial actuation cycle due to the biasing load enacted by the torsion spring arm. When the heating is complete, the specimen cools through radiation and the actuator undergoes forward transformation and returns to martensite. The heating process shown took much less time than the cooling process. To calculate the temperature lost to the surroundings, the torque tube was modeled as a black body.

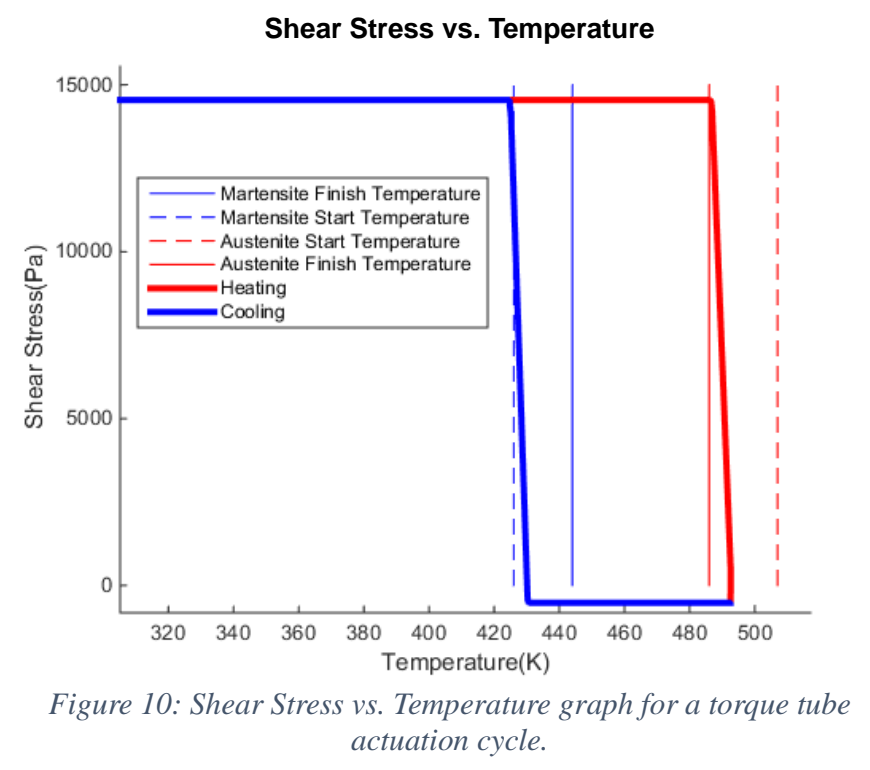

actuation cycle. 


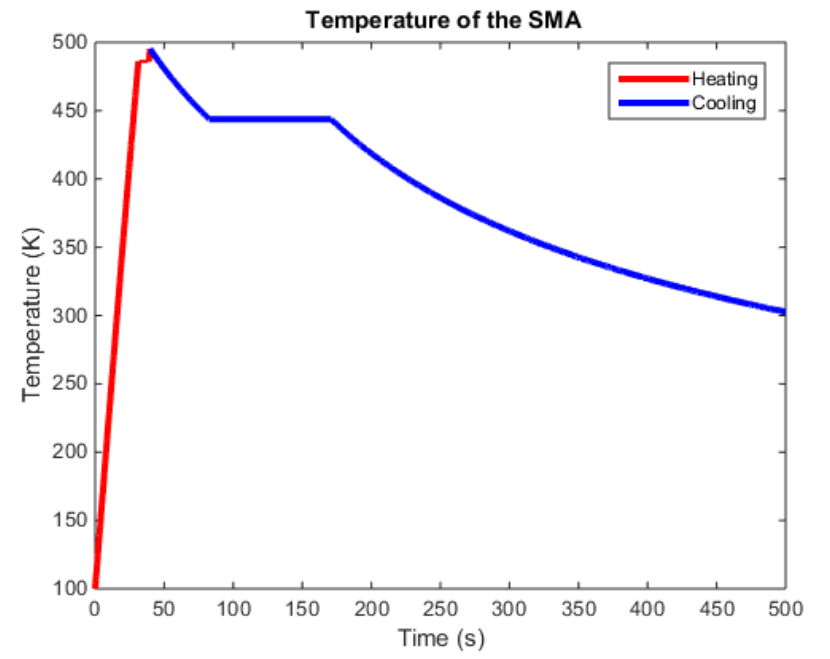

Figure 11: Temperature vs. Time graph for the torque tube actuation cycle.

For the purposes of this design, the torque tube was not required to complete a full actuation cycle. Due to the latent heat of transformation and power restrictions, the optimal design took advantage of this option and utilized approximately $40 \%$ of the available TWSME. The limits on the outer radius were set to $3 \mathrm{~mm}$ and $13 \mathrm{~mm}$ as an upper bound. The limits for tube thickness were $1 \mathrm{~mm}$ and $4 \mathrm{~mm}$. The power limits for the DoE were $1 \mathrm{~W}$ and $50 \mathrm{~W}$ and the cost function was set to minimize the power usage while not exceeding the stress or time limits.

This optimization program was checked against the previously made model to confirm its accuracy. One of the drawbacks to this model is that the transformation of the torque tube happens very quickly, making the degrees of twist liable to rapid change. This magnifies truncation errors caused by large time steps in the program.

For this project, the torque tube selection tool determined that the following parameters: outer radius and thickness needed to minimize power usage is a $3.6 \mathrm{~mm}$. outer radius and a $1.2 \mathrm{~mm}$ thickness. With these tube dimensions the tube will twist to about 46 degrees of rotation in 50 seconds using 50 watts of power.

The operation of the solar array deployment system, shown schematically in Figure 12, can be broken down into eight distinct stages, based on which SMA parts are being heated. When the satellite is ejected from the launch vehicle, all power in the deployment system will be off, and the spring and torque tube will be cold (initial state/retracted). First, the latch will be retracted prior to the actuation of the torque tube. This will allow the solar panel to open freely without contacting the latch. After opening, the latch will then be extended by allowing the nitinol spring to relax. This will fix the panels in a deployed state with both SMA components cold. In order to avoid unnecessary stresses on the torque tube in the deployed state, a one-way gear system was developed and is pictured in the following section. To retract the solar array, the torque tube will be heated removing the load on the latch, which will, in turn, be retracted via resistive heating. While the latch is still retracted, the NiTiHf torque tube will be allowed to cool and the panels will return to their retracted state. Finally, after the solar panel is fully retracted, the nitinol spring is allowed to cool and the system re-enters the fully retracted state.

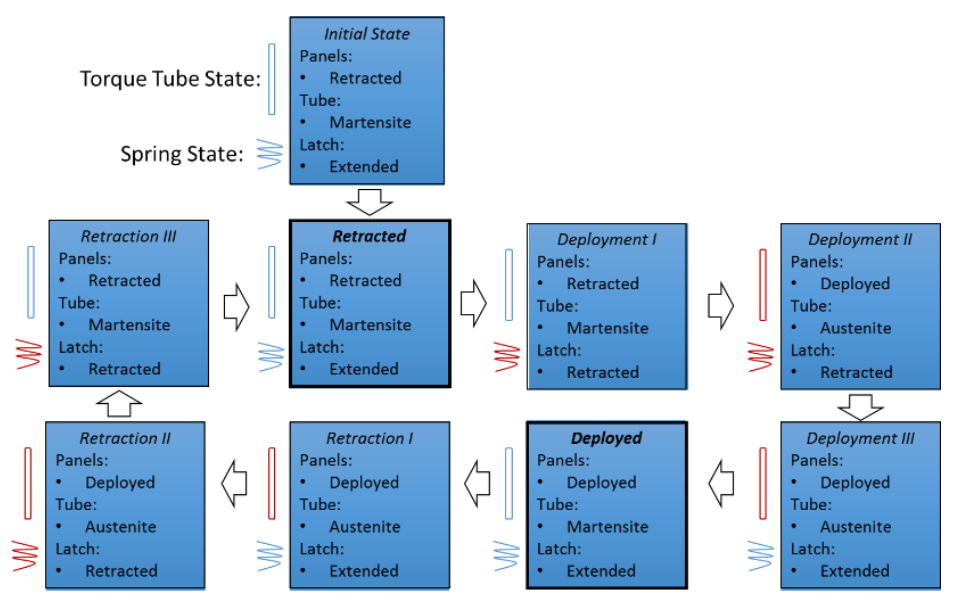

Figure 12: Operational schematic of the solar array deployment mechanism

\subsubsection{Model Validation and Prototype Development}

The torque tube model which was implemented in the design tool had been previously used for the design of a twisting airfoil [23] and was based on the constitutive model presented in [24]. In order to validate the new implementation of the model, three isobaric cycles at various stress levels were carried out and the experimental results can be seen in Figure 13 where they are compared with the modeling predictions. Materials properties were obtained from available literature [25].

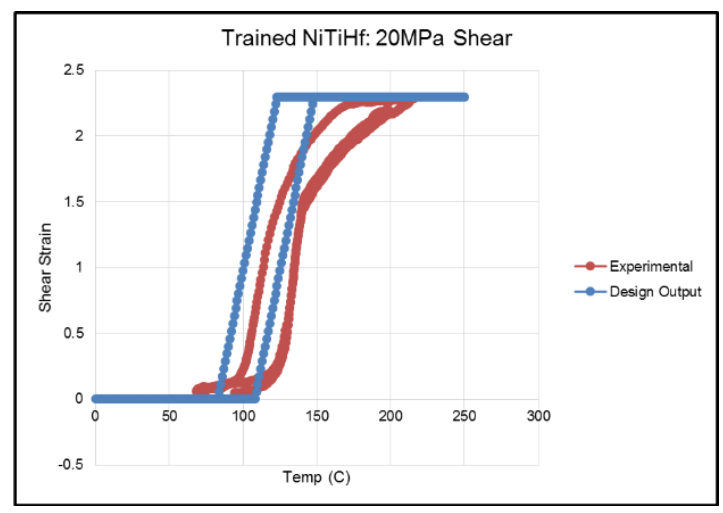




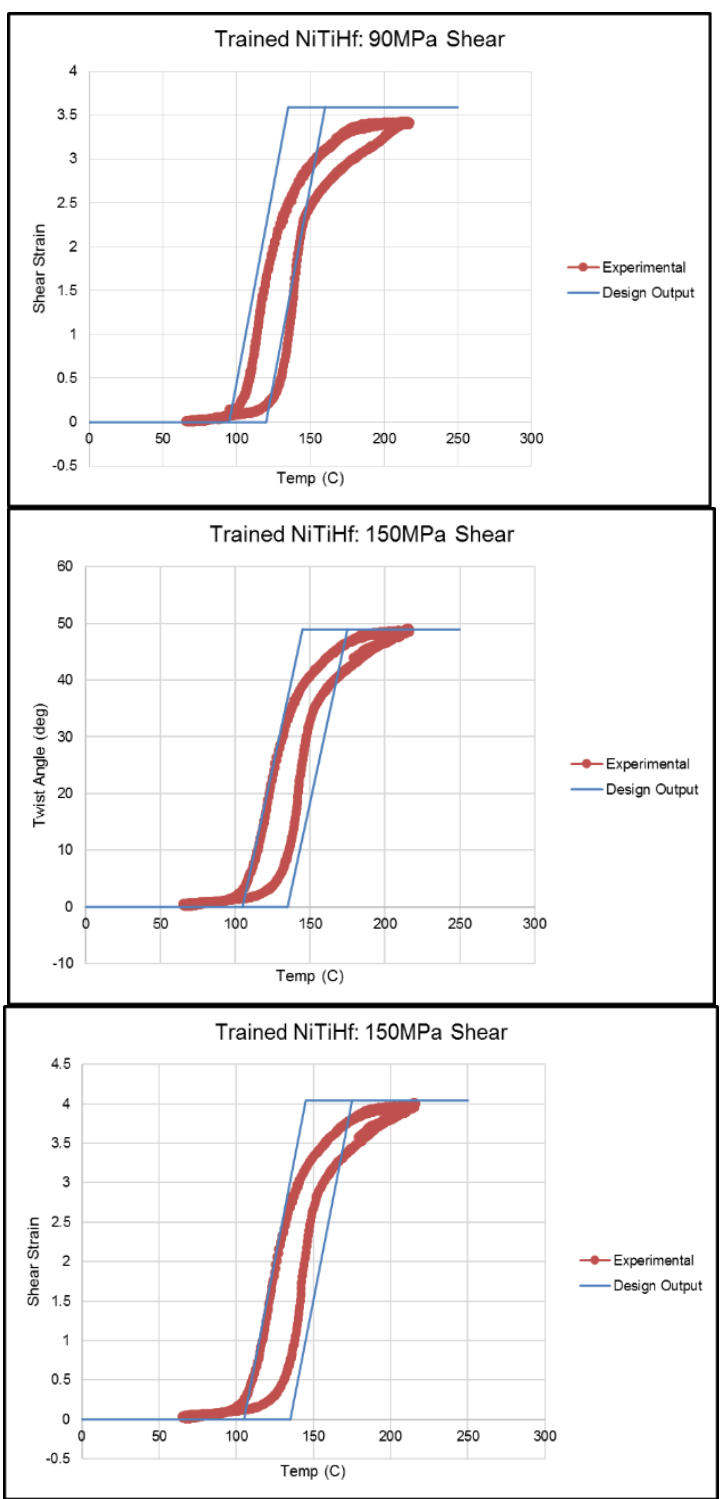

Figure 13: Experimental Validation of Torque Tube Model. Note: $150 \mathrm{MPa}$ data used to calibrate model.

Once the model implemented in the torque tube selection tool was validated, the prototype was developed around the equiatomic NiTi torque tube shown in Figure 14 due to material availability.

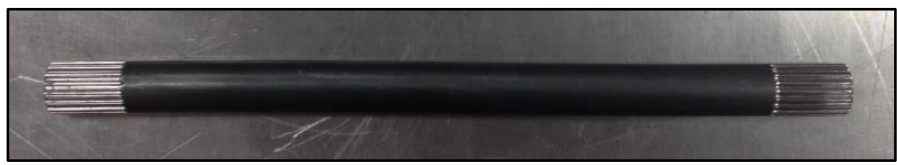

Figure 14: Torque tube actuator utilized in prototype development. Dimensions: 0.375" diameter, 0.1" thickness, 8" length

The completed prototype is shown in Figure 15 along with the SolidWorks drawing of the system, which was developed in order to $3 \mathrm{D}$ print the frame, gear system, and latching mechanism.
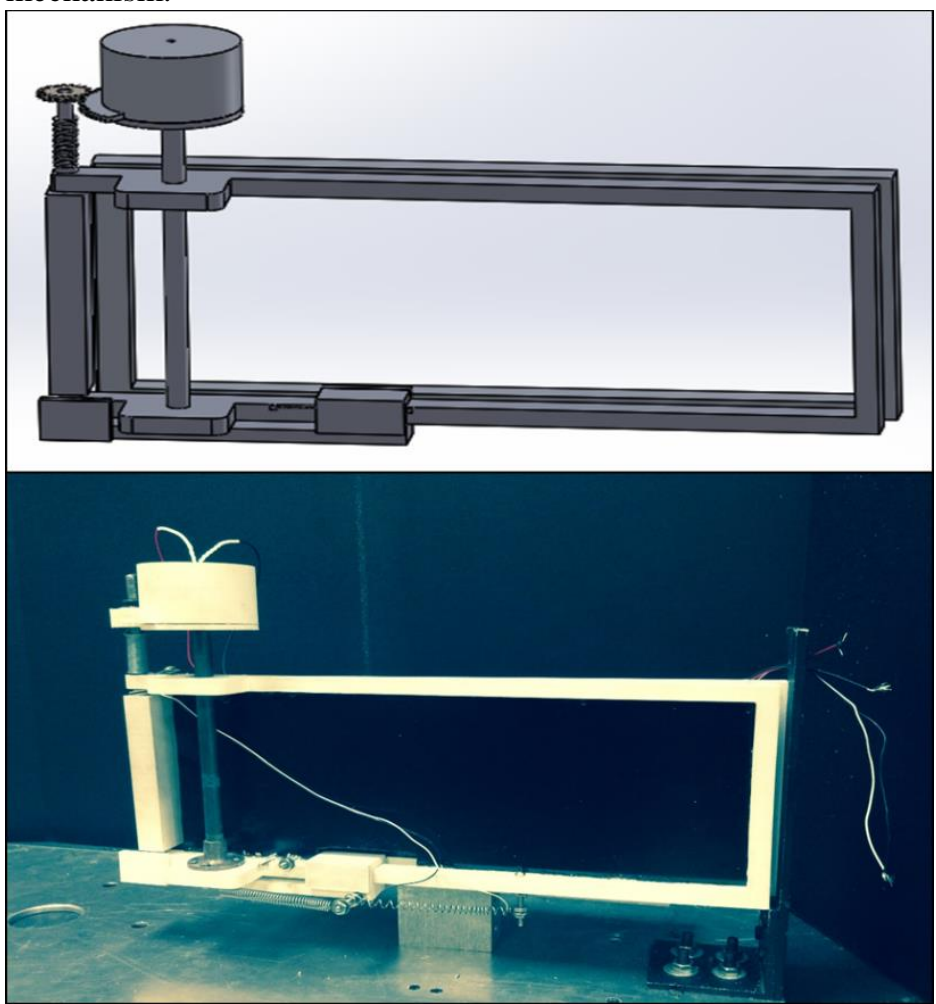

Figure 15: SolidWorks drawing of prototype (top) and assembled prototype after testing

The gear system amplifies the rotation of the torque tube such that the tube is only heated until it obtains $49^{\circ}$ of rotation. In addition to amplifying the rotation, the gear system also allows the torque tube to rest in a near-zero stress state. A slice of this one-way mechanism can be seen in Figure 16 along with a closeup of the latch mechanism.
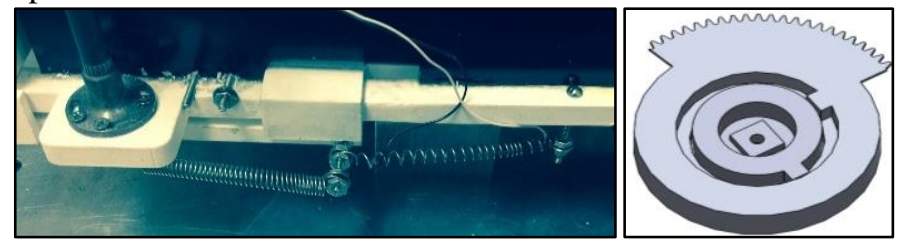

Figure 16: Close-up of latch mechanism (pseudoelastic spring on left, actuator spring on right) and slice of SolidWorks rendering of gear system (torque tube attached to center)

In order to complete the design challenge, 300 cycles were performed in continuous operation in order to demonstrate the robustness of the design. In the test setup shown in Figure 17, a laptop controls the heating and cooling through a LabVIEW program and National Instruments Data Acquisition (NI-DAQ) board. 

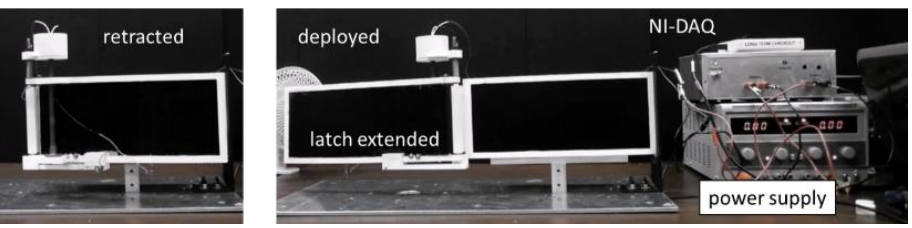

Figure 17: Test Setup for Repeatability Test

\subsection{SUNSHADE SOLAR DESIGN}

\subsubsection{SMA Deployed Satellite Solar Array}

Shape memory alloys present a unique solution for deployment mechanisms for solar arrays in satellite applications. Commonly used solar array deployment systems consist of mechanical and electro explosive devices (EEDs). These devices are used for deployment of the array during different phases of the transfer orbit and synchronous orbit [26]. Unfortunately, they lack reusability and multi-functionality, limiting their overall effectiveness and use in clever design solutions. SMA's provide the opportunity for unique design choices which combat these shortcomings and allow for more advanced deployment and control design.

\subsubsection{Design Challenge}

CASMART issued a design challenge to students of Colorado School of Mines to explore the use of shape memory alloys in solar array deployment mechanisms. This case study focuses on the design process, analysis, and results obtained by one of these student teams in using SMAs for these deployment mechanisms.

\subsubsection{Design}

The solar array was designed small scale to test the feasibility of the actuation and control system, while an FEA analysis provided results for a full scale design. The overall design was modeled after an umbrella, with solar panels being mounted on the canopy. The deployment and control mechanism used SMAs to provide force along the primary axis to deploy the umbrella. The structure is mounted on a ball joint to provide a means for tilting the panels. The tilting of the array allows for increasing incident light and power generation from the panels. SMA actuators provide the force required for pulling the panels into position, until a latch mechanism holds the panels in place. The tilting control of the array is provided using additional SMA actuators. These are mounted along four corners, up to the base of the canopy. By selectively controlling these actuators, tilt in any direction can be achieved. By implementing good control design and with the addition of photo resistors or other light sensitive electronic components, it is possible to achieve solar tracking using this method.

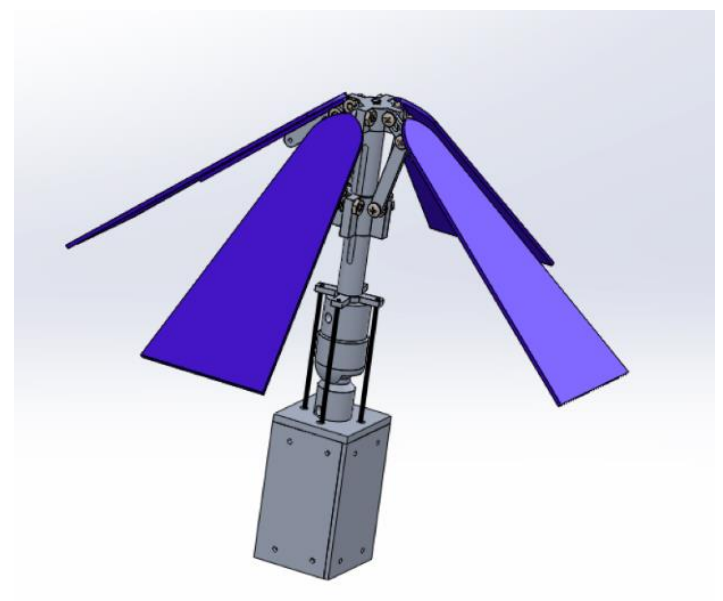

Figure 18: Model of small scale solar array

\subsubsection{Alloy Selection and Actuator Control}

Nitinol springs from Dynalloy were used to provide the actuation necessary for both the deployment and tilting control of the array. The Flexinol $90^{\circ} \mathrm{C}$ springs were used for actuators, while the actuation itself was driven through the use of Joule heating. The control of the actuators requires special attention. In a near vacuum environment, heat dissipation will be primarily from radiation, thus cooling of the SMA actuators is a concern. For initial deployment, this is not a significant issue, as these are intended to be used once. For the small scale model, power consumption for deployment was calculated at $23 \mathrm{~W}$. For a two second actuation period, this is low enough power consumption that onboard batteries could be used. The power requirements will scale up in a full-size design; however, the reduced heat dissipation will also lead to less power needed for full actuation.

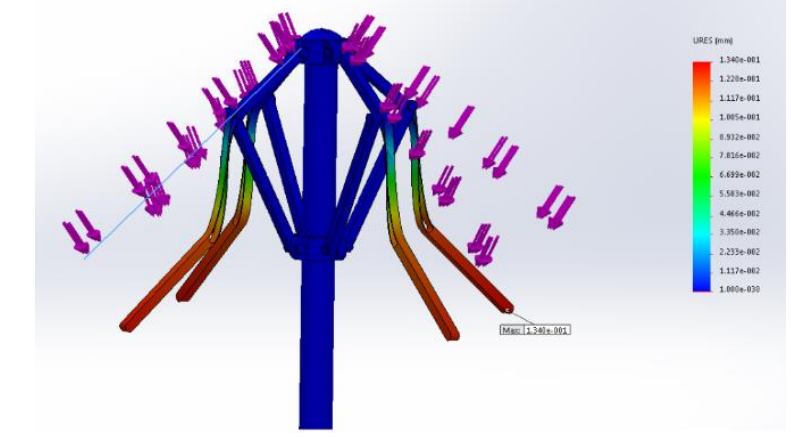

Figure 19: FEA analysis of large scale model. Shows minimal arm displacement under load of $200 \mathrm{lbs}$

\subsubsection{Scalability and Future Considerations}

The student team concluded that a full-scale solar array with SMA actuator driven deployment, as well as tilt control is a feasible prospect. FEA analysis done shows the small-scale design can be scaled up to accommodate over 200lbs of weight per umbrella arm, as well as the scalability of using SMAs for the deployment.

SMAs show promise for the use of solar array deployment in satellite applications. Compared to current technology, they 
offer more flexibility, reusability, and can easily be integrated into mechanical designs. They also offer the ability to enhance current arrays through the use of additional actuators. This was demonstrated in the design via including tilt actuators, which increases the light received by the panels and power produced. Future ideas include passive SMA tilt systems for the solar array, where sunlight is the source of actuation through radiative heating. Through the right control scheme, it might allow for tracking capabilities with minimal power draw from the solar panels themselves.

\subsection{SHEET - PASSIVE GAS TURBINE CORE AIRFLOW TEMPERATURE CONTROLLER}

\subsubsection{Problem statement}

Large civil aero engines are very mature products that have seen steady improvement over several decades. Additional variability or control has the potential to provide marked improvements at certain parts of the operating cycle, but this must be achieved whilst maintaining safety and providing a business and environmental benefit.

One potential improvement can be seen is in the control of cooling flows to maintain a constant core temperature. A schematic of a gas turbine engine is shown in Figure 20. The primary function of the core engine is to provide power to drive the fan which forces the bypass airflow down the bypass duct and subsequently through the nozzle to provide the majority of the engine thrust. The core airflow from the core engine exits coaxially with the bypass airflow and also contributes to the overall thrust. Air temperatures in the core engine reach over $1500^{\circ} \mathrm{C}$ which require considerable cooling of the parts in order to maintain component life. Some of the heat also comes through the core casing. The area around this must be cooled to prevent external components becoming overheated. Air is taken from the bypass flow and passed over the core casing to pick up the heat before exiting again into the bypass flow. Any air that does not follow a simple path through the engine

$+$

e will cause a reduction in efficiency, which must be minimized. The flow is largely controlled by the area of the duct where it returns to the bypass flow, the size being chosen for the condition where maximum cooling is needed such as takeoff or climb. This leads to excessive cooling at other conditions where heat input is reduced such as at cruise. A method of controlling to a constant exit air temperature over all flight segments would give a significant improvement in overall fuel burn. This will also significantly reduce the airflow when the heat input is low and a subsequent efficiency improvement.

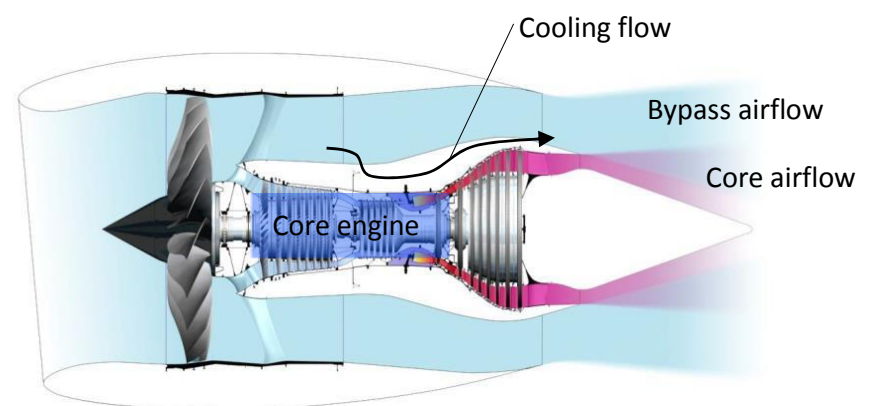

Sentence is off. The first two things it does end in ing. They are "including" and "increasing" so the third one needs to be something like producing power.

Sentence is off. The first two things it does end in ing. They are "including" and "increasing" so the third one needs to be something like producing power.

\section{Figure 20: Schematic of gas turbine engine showing core engine, cooling flow, bypass airflow and core airflow.}

\subsubsection{Objective}

Shape memory alloys can provide a method for varying the area of the exit vent as a method of controlling the temperature of the air flowing through it since a single component may simultaneously serve as a temperature sensor, structural material, and actuator. In this project, CASMART challenged the students to design and demonstrate a passive core airflow temperature control mechanism that opens to add bypass air to the mixture in cases of extreme temperatures, but remains closed to preserve the efficiency of the engine at all other times. In full-scale gas turbines, the desired operating temperature of the core airflow is $300{ }^{\circ} \mathrm{C}$. While new SMAs have been developed to operate at this temperature, they are still limited in commercial availability. Thus, for the challenge, students were asked to demonstrate a capability of maintaining a core airflow temperature of $90{ }^{\circ} \mathrm{C}$ in their models, which would be achievable using commercial NiTi wires. The design requirements and specifications are given in Table 5.

Table 5: Requirements and specifications of the case study.

\begin{tabular}{|l|l|}
\hline Requirements & Specifications \\
\hline Safe & $\begin{array}{l}\text { The design should meet } 99 \% \text { or better } \\
\text { reliability. This success rate should be } \\
\text { documented for a samples size of at least } \\
100 \text { consecutive operations of the final } \\
\text { model. The application should be service- } \\
\text { free for a year. Each plane may fly } 2 \text { routes } \\
\text { per day. }\end{array}$ \\
\hline
\end{tabular}




\begin{tabular}{|l|l|}
\hline Lightweight & $\begin{array}{l}\text { The full-size design should add no more } \\
\text { than a pound of weight to a full-size } \\
\text { engine. The weight of the model should be } \\
\text { scaled appropriately. Weight minimization } \\
\text { is highly important, as additional weight } \\
\text { requires more fuel and compromises } \\
\text { improvements realized from controlling } \\
\text { the core airflow temperature. }\end{array}$ \\
\hline Cost-Effective & $\begin{array}{l}\text { The model must be within a \$200 budget; } \\
\text { however, every dollar should be justified. }\end{array}$ \\
\hline Scalable & $\begin{array}{l}\text { The size of the hotspots in the full-size } \\
\text { turbines may vary, so the design must be } \\
\text { easily modified to match any size hotspot. }\end{array}$ \\
\hline Passive & $\begin{array}{l}\text { The design must be completely passive. It } \\
\text { must only react to the temperature of the } \\
\text { surroundings with no need for any } \\
\text { electronic input. }\end{array}$ \\
\hline
\end{tabular}

\subsubsection{Design concept}

The concept of this case study is to essentially replace the wouldbe hotspots with metallic bilayer actuator sheets of aluminum and SMA. The design approach is modular to allow for any size and number of hotspots. The originally designed aerodynamics and efficiency of the engine are preserved except during periods of high load, such as takeoff and climb. During these times the bilayers actuate and are removed from the hotspot locations, allowing cooling flow to enter the core. The open position of the bilayers is illustrated in Figure 21. With sufficient cooling the bilayers reverse actuate, restoring engine aerodynamics and efficiency. The SMA is the inside layer, exposed to the core airflow while the aluminum is the outside layer, exposed to the bypass airflow (Figure 20). The bilayer is in a normally closed position (detwinned martensite), as if the hotspot material had not been removed. As the core airflow temperature increases, the SMA sheet actuates (austenite) through phase transformation, exposing the SMA sheet to bypass airflow. The bypass airflow cools the SMA sheet, reverse transforming it to accommodate (twinned) martensite. The aluminum sheet, which is elastically deformed by the SMA during forward transformation, provides force to detwin the martensite and restore the bilayer to its original closed position.

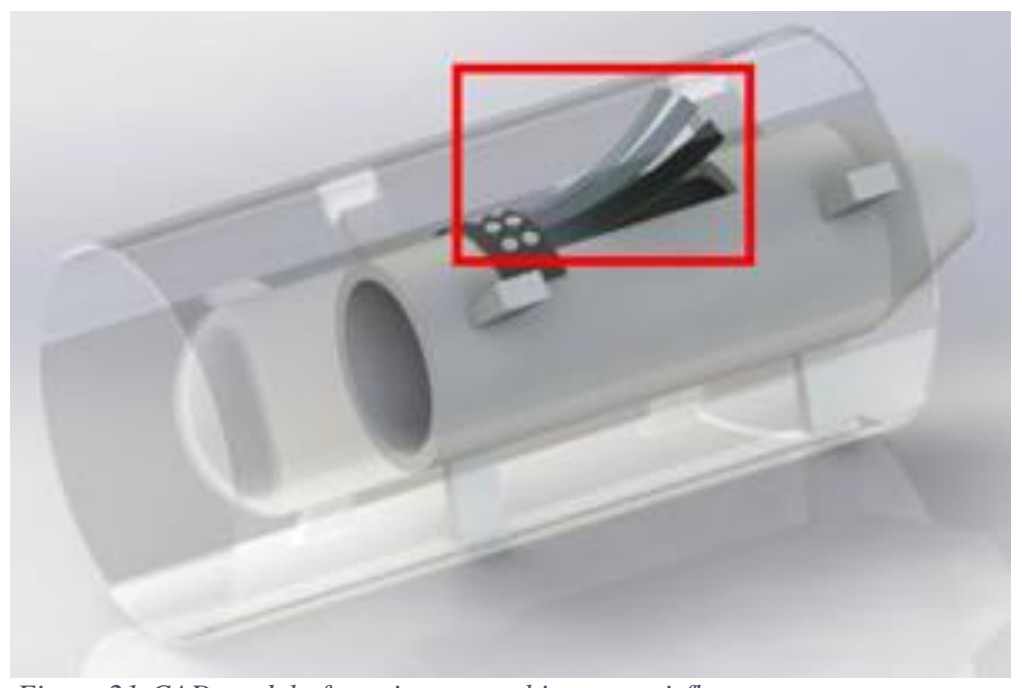

Figure 21:CAD model of passive gas turbine core airflow temperature controller design showing metallic bilayer strips in open position, boxed in red.

\subsubsection{Final design}

This case study helps to highlight the need for and advantages of SMA design tools such as those used in other case studies of this article, as a sheet design tool was not available. The solution achieved through an iterative approach for SMA design in this case study could have been further optimized in a much timelier manner with a design tool. A design tool for relating heat treatment, transformation temperature, and actuation force as a function of sheet geometry would have been most useful and is currently under development.

\subsubsection{Heat treating}

The original material was superelastic NiTi ribbon with a transformation temperature of approximately $25^{\circ} \mathrm{C}$ and dimensions of 0.02 " thickness, $0.455^{\prime}$ " width and cut to length. Heat treatments were performed to shape-set and raise the transformation temperature to make the material a suitable actuator for an ambient operating temperature greater than $35^{\circ} \mathrm{C}$. A circular arc was chosen for shape setting as this would promote uniform stresses along the bilayer length. Heat treatment serves to shape set the material by recrystallizing the grains to the geometry the material is constrained to during heat treatment. It serves to raise the transformation temperature by forming $\mathrm{Ni}_{4} \mathrm{Ti}_{3}$ precipitates. Since these precipitates are $\mathrm{Ni}$ rich, the matrix become $\mathrm{Ti}$ rich, raising the transformation temperature. The volume fraction of precipitates increase as a function of time. Altering material composition and microstructure also affects actuating force. Because of this, an iterative heat treatment 
approach was used to find a time that would produce a transformation temperature above $35{ }^{\circ} \mathrm{C}$ while maximizing actuating force. Heat treatment results performed at $350{ }^{\circ} \mathrm{C}$ and water quenched are summarized in Table 6. The 17-hour heat treatment time was chosen as it satisfied the transformation temperature and actuating force criteria.

Table 6: Summary of resulting transformation temperatures and maximum forces from heat treatments.

\begin{tabular}{|l|l|l|}
\hline $\begin{array}{l}\text { Heat treatment } \\
\text { time (hours) }\end{array}$ & $\begin{array}{l}\text { Transformation } \\
\text { temperature }\left({ }^{\circ} \mathbf{C}\right)\end{array}$ & Max force (N) \\
\hline 1 & 35 & 2.8 \\
\hline 2 & 35 & 3.1 \\
\hline 17 & 47 & 3.1 \\
\hline 22 & 49 & 2.6 \\
\hline
\end{tabular}

\subsubsection{Prototype}

The final prototype consists of clear acrylic tube for the outer cowling, PVC tube for the inner cowling into which the metallic bilayer is integrated, and a desktop computer fan to provide airflow (Figure 22). A single 1.05" wide, 0.025" thick 3003-H14 aluminum sheet is clamped to two NiTi ribbons of equal length. The PVC inner cowling was milled to provide an inset for the metallic bilayer as shown in Figure 23. Engine heating was simulated using a heat gun as seen in Figure 24a with the metallic bilayer in the closed position. The metallic bilayer in open position after heating is shown in Figure 24b.

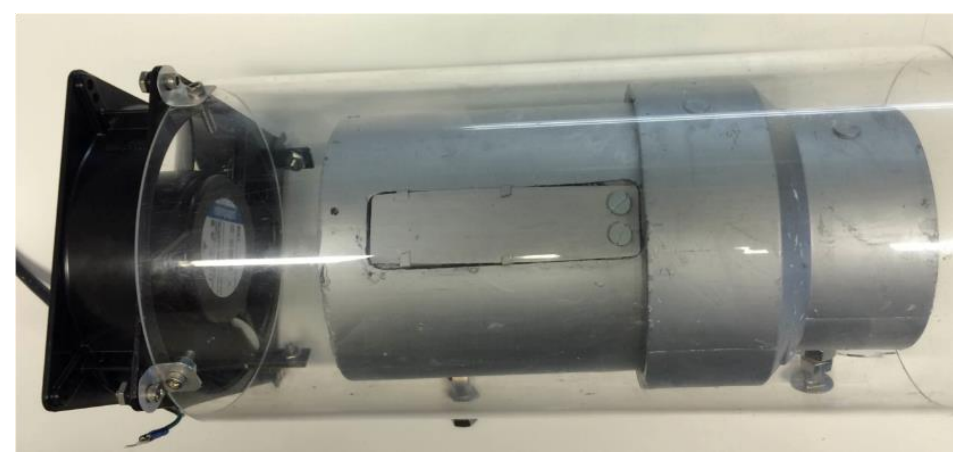

Figure 22: Final prototype of passive gas turbine core airflow temperature controller showing clear acrylic tube outer cowling, painted PVC inner cowling with inset metallic bilayer and desktop computer fan.

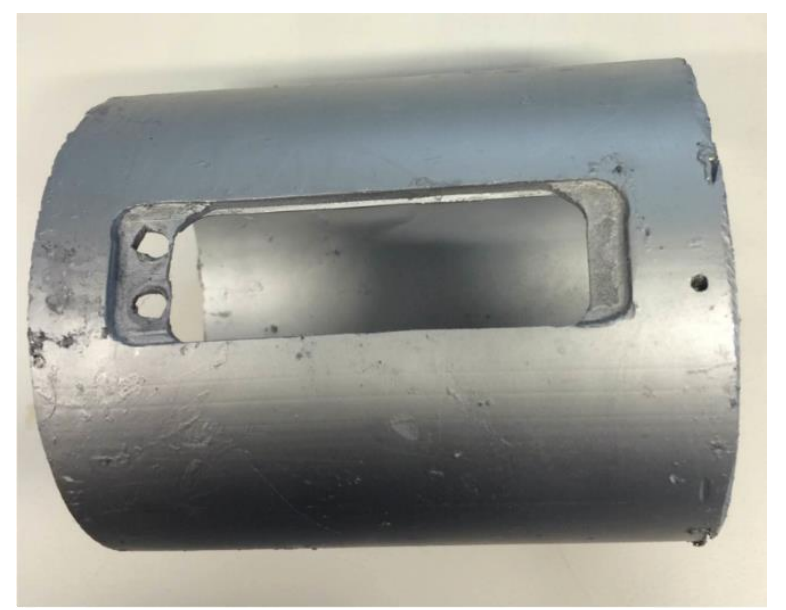

Figure 23: Milled metallic bilayer inset of PVC inner cowling.

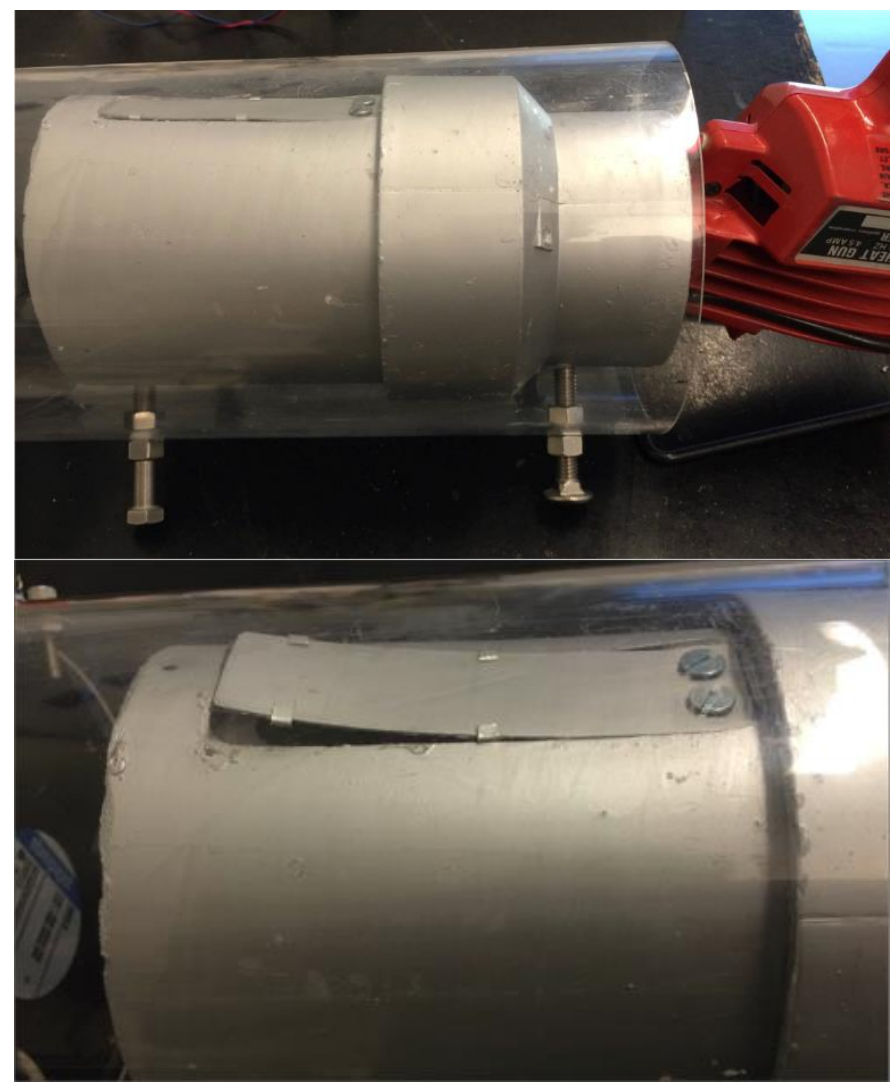

Figure 24: a) Metallic bilayer in closed position with heat gun place for engine heating simulation (top) and b) Metallic bilayer in open position after heating (bottom).

\subsubsection{Scaling considerations}

The modular design approach makes this case study scalable to any size and number configuration. As commercial binary NiTi is not suitable for a real-world application due to low transformation temperature, regardless of heat treatment, a different composition SMA would be required. One consideration for a high temperature SMA are NiTiHf alloys, as 
the hafnium addition considerably raises the transformation temperature and the amount of hafnium addition can be used to tune the critical temperatures for desired operating conditions. However, the addition of hafnium tends to reduce the actuation strain.

\subsubsection{Cantilever Beam Bending Calculations}

The following equations are included for the purpose of design scalability.

The displacement of the beam that provides the restoring force for the SMA

$$
\delta=\frac{F L^{3}}{3 E I}
$$

where $\delta$ is beam displacement, $F$ is force produced by SMA, $L$ beam length, $E$ is beam modulus of elasticity and $I$ is beam area moment of inertia.

$$
I=\frac{W H^{3}}{12}
$$

where $W$ and $H$ are beam width and height, respectively.

\subsubsection{Shear and normal stress}

The shear moduli of SMA austenite and martensite phases is given by

$$
G_{i}=\frac{E_{i}}{2\left(1+v_{i}\right)}
$$

where $G$ is shear modulus, $E$ is modulus of elasticity and $v$ is Poisson's ratio. The subscript $i$ denotes austenite (a) or martensite $(m)$. Shear stress for each phase is then given by

$$
\tau_{i}=\gamma G_{i}
$$

where $\tau$ is shear stress and $\gamma$ is shear strain. Normal stress is given by

$$
\sigma_{x i}=-\frac{M y}{I}
$$

where $\sigma_{x}$ is x-direction normal stress, $M$ is bending moment and $y$ is distance away from neutral axis.

\subsection{CORVETTE ACTIVE HATCH REDESIGN}

The case studies presented in this section focused on redesigning a component in the 2014 Corvette Stingray that utilizes an SMA. The Stingray has a well-sealed cabin and owners often have trouble closing the hatch after it has been opened. To relieve pressure in cabin, an active hatch vent (AHV) assembly resides in the bottom of the back bumper between the car body and bumper, as shown in Figure 25. When the hatch is opened, electrical current flowing to the hatch vent is routed through an SMA wire, heating it and causing the austenite to transform to martensite. This phase transformation upon heating results in a contraction of the wire, which in turn pulls on a gearing mechanism that opens the AHV flaps. While the hatch is open, a printed circuit board (PCB) continues to supply a trickle charge to keep the wire heated (and thus contracted), so that the flaps remain open. When the hatch is closed, the current supplied to the SMA wire is stopped, and the wire cools naturally. Upon cooling, the phase transformation is reversed allowing the wire to be stretched back out and the AHV flaps to close via a return spring.

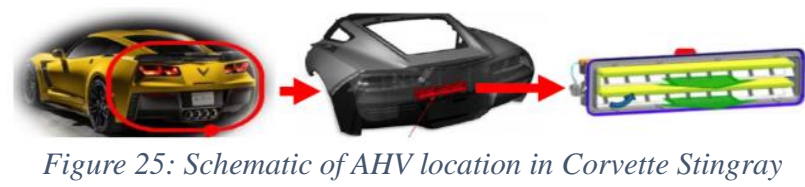

The AHV unit currently in production works to relieve pressure in the Stingray and allow for easier closing; however, opportunities for improvement of the AHV exist. The following case study was aimed at design and fabrication of an AHV assembly with a reduced footprint and lower production cost, while still meeting the same actuation temperature range and actuation time criteria, described in further detail in the following section.

\subsubsection{Design Criteria}

For each case study, the new components were required to fit into a $38.1 \mathrm{~mm} \times 76.4 \mathrm{~mm} \times 12.7 \mathrm{~mm}$ ( 1.5 in $\times 3.0$ in $\times 0.5$ in) envelope. The vent flaps needed to achieve an actuation angle of at least $40^{\circ}$ (from closed to fully open). Full opening of the flaps had to be completed within five seconds of applying current to the wire, and full closing had to be completed within 15 seconds of power being cut (with the vent assembly at room temperature). To prevent carbon monoxide infiltration into the passenger cab, a fail-safe mechanism was also desired to ensure that if the AHV failed, the flaps would be in the closed position. The AHV was required to operate when the entire assembly experiences ambient temperatures between -40 to $60{ }^{\circ} \mathrm{C}\left(-40\right.$ to $\left.140{ }^{\circ} \mathrm{F}\right)$. An upper limit of $70^{\circ} \mathrm{C}\left(158{ }^{\circ} \mathrm{F}\right)$ was preferred to prevent the vent flaps from remaining open at elevated temperatures. The actuation temperature of the SMA element was preferred to be $110^{\circ} \mathrm{C}\left(230^{\circ} \mathrm{F}\right)$ (obtained from current applied to the element). Both case studies utilized Flexinol® ${ }^{\circledR}$ SMA elements (springs or wires) rated to actuate at $90{ }^{\circ} \mathrm{C}$, and both designs relied on applied stresses on the SMA elements to increase the actuation 
temperature. An additional focus of the case studies was to use SMA design tools to calculate the required stroke and force needed to actuate the vent for each design. The output from the SMA design tool in turn assisted in determining the best geometry and specific dimensions of the SMA element in each case study.

\subsubsection{Redesign with SMA spring Actuation}

An "opposed-pulley" design is used to actuate the flaps in the Corvette AHV re-design, as shown in Figure 26 a) SolidWorks model and b) photograph of completed assembly. A 3D-printed pulley was mounted on the shaft of the vent with an SMA spring attached to one side of the pulley, and a steel bias spring attached on the opposite side. An insulated wire was crimped to the SMA spring to supply current, and thereby resistively heat it. Resistive heating causes the SMA spring to contract, rotating the pulley and opening the vent flaps. Once current stops flowing, the SMA spring cools and relaxes under the biasing force of the steel spring and the weight of the vent flaps, causing the vent to return to the closed position. The springs were secured to bolts that were screwed into the side of the AHV unit. Details of each component in the design are given below. Figure 26 shows the a) SolidWorks model and b) photograph of completed assembly.

A Flexinol ${ }^{\circledR}$ shape-memory alloy spring with wire diameter of $0.51 \mathrm{~mm}(0.02 \mathrm{in})$, outer diameter of $2.79 \mathrm{~mm}$ ( $0.11 \mathrm{in})$, coil index of 4.471 , and $90^{\circ} \mathrm{C}$ actuation temperature was used for actuation. A steel music wire extension spring with a 1 " rest length and a spring constant of $0.5 \mathrm{lbf} / \mathrm{in}$ was used as the bias spring.

The pulley was $5.97 \mathrm{~mm}$ (0.235 in) thick, with a lever arm length of $9.53 \mathrm{~mm}(0.375 \mathrm{in})$ and $3 \mathrm{D}$ printed from ABS. Two posts were printed on either side of the pulley for attachment of the SMA and biasing springs. The posts on the pulley were positioned such that with a 40 degree rotation, the stroke of each spring would remain as linear as possible. This keeps the force profile smooth during operation and reduces the chance of mechanical failure while still allowing for the full actuation length needed to open the vent.

A timing circuit utilizing an Arduino combined with a bench power supply setup to simulate a $12 \mathrm{~V}$ car battery was used for testing and demonstration purposes.

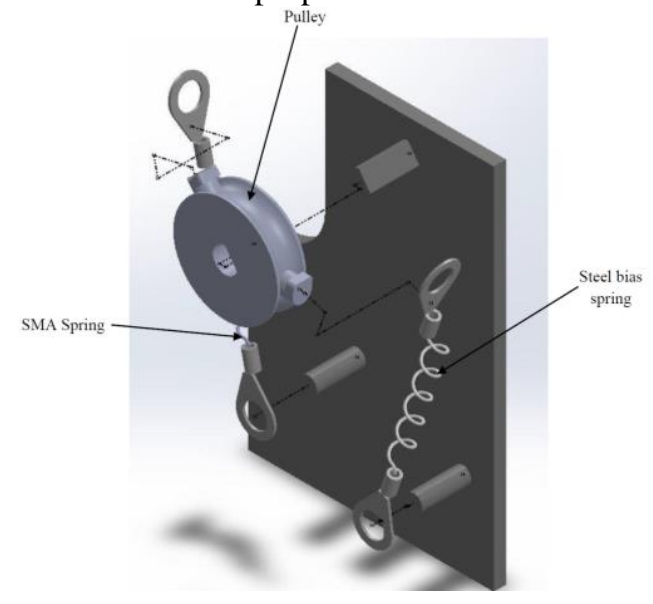

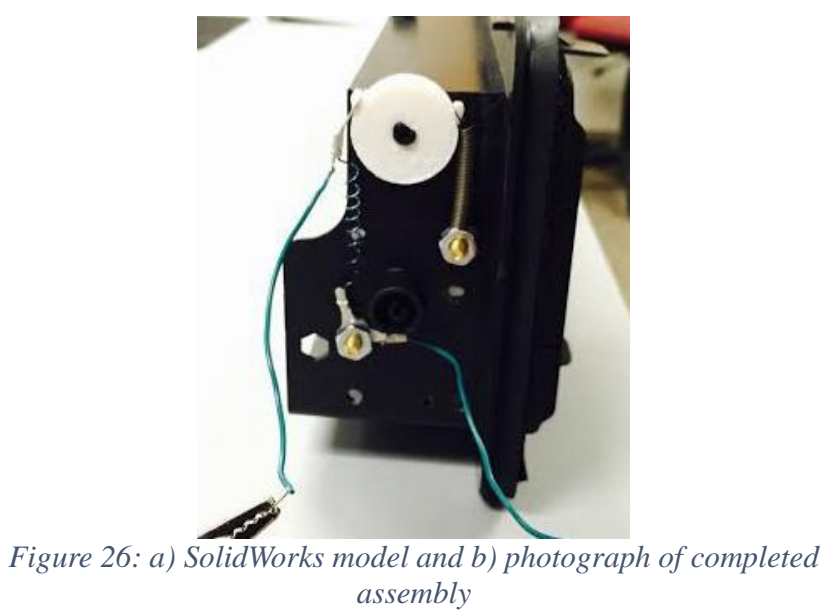

\subsubsection{Calculations and Use of Design Tools}

The required stroke length, spring properties, and actuation force required by the spring and used for subsequent calculations are shown in Figure 27. As previously mentioned, to increase the actuation temperature of the SMA element (initially $90{ }^{\circ} \mathrm{C}$ ) to $110{ }^{\circ} \mathrm{C}$, it was necessary to increase the stress applied to the SMA spring. A maximum stress of $250 \mathrm{MPa}$ was chosen to avoid plastic deformation of the spring, based on spring manufacturer ratings.

The Flexinol® spreadsheet provided by Dynalloy predicted that $4.6 \mathrm{~mm}$ of displacement would be possible per coil, thus requiring only two 2 active coils to achieve a desired stroke length of $6.3 \mathrm{~mm}(0.248 \mathrm{in})$. However, testing showed that 6 active coils were necessary to achieve the desired stroke. Figure 28 shows calculations performed to determine the minimum and maximum shear stresses experienced by the SMA spring. The minimum and maximum shear stresses in the SMA spring were calculated to be $190 \mathrm{MPa}$ and $222 \mathrm{MPa}$ respectively, both below the $250 \mathrm{MPa}$ endurance limit.

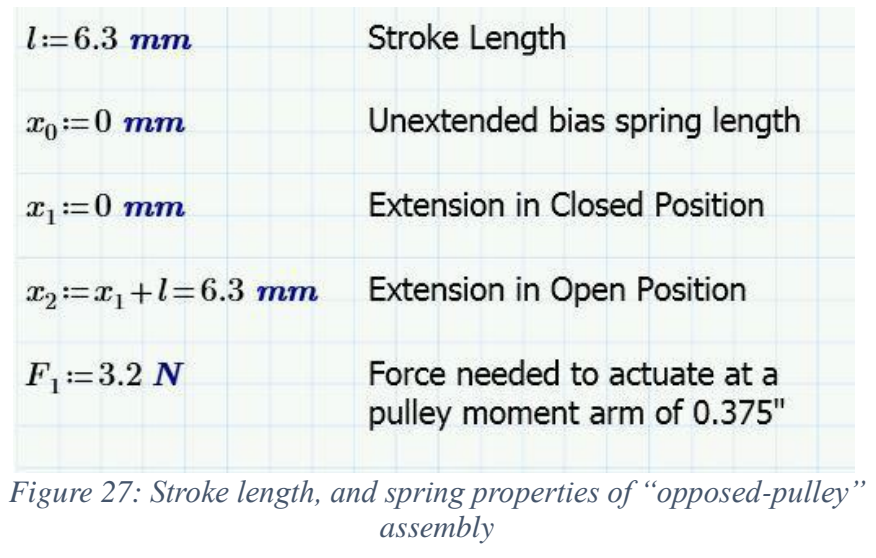




$$
\begin{array}{ll}
F_{\text {max }}:=k_{\text {bias }} \cdot\left(x_{2}-x_{0}\right)+F_{1}=3.752 \mathrm{~N} & \text { Max. Force in SMA Spring } \\
\tau_{\text {max }}:=\frac{\left(8 \cdot \mathrm{W} \cdot D_{\text {mean }} \cdot F_{\text {max }}\right)}{\pi \cdot d^{3}}=222.279 \mathrm{MPa} & \text { Max. Shear Stress in the SMA Spring } \\
F_{\text {min }}:=F_{1}+k_{\text {bias }} \cdot\left(x_{1}-x_{0}\right)=3.2 \mathrm{~N} & \text { Min. Force in SMA SPring } \\
\tau_{\text {min }}:=\frac{\left(8 \cdot W \cdot D_{\text {mean }} \cdot F_{\text {min }}\right)}{\pi \cdot d^{3}}=189.595 \mathrm{MPa} & \text { Min. Shear stress in SMA Spring } \\
\Delta_{\tau}:=\tau_{\text {max }}-\tau_{\text {min }}=32.684 \mathrm{MPa} & \text { Difference Between Min. and } \\
& \text { Max. Shear Stress }
\end{array}
$$

Figure 28: Calculations for minimum and maximum shear stress in the SMA spring

The SMA Design Spreadsheet provided by CASMART was used to create a plot of force versus deflection for the SMA spring, as shown in Figure 29. Horizontal lines are plotted at 3.2 $\mathrm{N}$ and $3.72 \mathrm{~N}$, the calculated minimum and maximum loads, respectively. The difference in the $\mathrm{x}$-value where the maximum force line crosses the austenite line and where the minimum force line crosses the martensite line are indicative of the possible stroke. It should be noted that inputting the material and geometric parameters for the SMA spring into the spring prediction tool predicted a maximum deflection of $2.9 \mathrm{~mm}$ (0.114 in), less than the deflection reported by Dynalloy. Deflections greater than $2.9 \mathrm{~mm}$ were observed during testing.

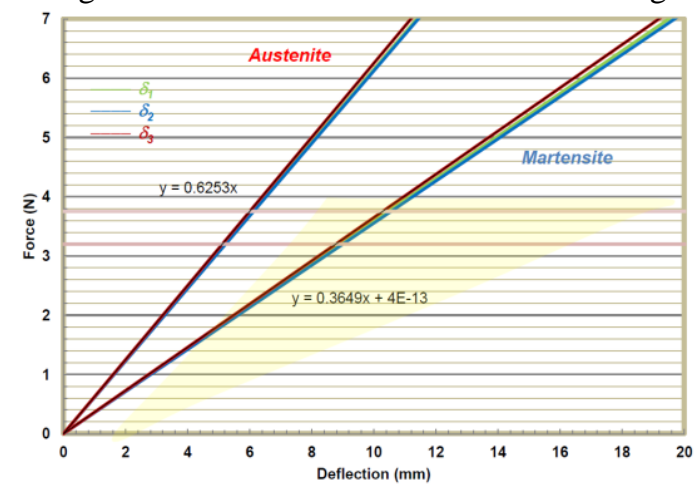

Figure 29: Force versus deflection plot generated from CASMART Design Spreadsheet for SMA spring

The diameter of the wire in the spring was increased to keep the maximum stress below $250 \mathrm{MPa}$ and still allow the application of enough stress to increase the actuation temperature. Increases in wire diameter resulted in increased cooling time for the spring, and in turn increased closing time of the vent flaps. Thus, the maximum wire diameter was limited to one that would not exceed the allotted $15 \mathrm{~s}$ maximum closing time.

\subsubsection{Prototyping and Testing}

The final prototype unit met the criteria outlined in the Overview section, except for closing time of the vent. A closing time of under $15 \mathrm{~s}$ at room temperature was preferred, while the actual closing time achieved with this design was about $20 \mathrm{~s}$. It is worth noting that the AHV closed a majority of the way in the first 10 s.
Consistent opening and closing of the vent flaps without deterioration in the SMA spring or actuation time was observed during 100 consecutive test cycles at room temperature. The vent opened completely in every case, implying that the stroke length remained constant over all cycles, and that the maximum stress experienced by the SMA spring did not exceed the $250 \mathrm{MPa}$ limit. Several test cycles were also completed at elevated temperature $\left(70^{\circ} \mathrm{C}\right)$, by placing the unit in a conventional oven and supplying power to the SMA. The oven temperature was verified using a handheld infrared laser thermometer. At elevated temperature, the vent flaps still opened and closed completely; however, the SMA cooling time increased to 30 seconds.

\subsubsection{Redesign with SMA Wire Actuation}

The proposed design used two SMA wires that looped through opposite ends of a cantilever mounted on the vent flaps and contracted in an opposing manner to open and close the flaps. Figure 30 shows the SolidWorks normal view of the proposed AHV design with the components indicated: cantilever arm, detent (mounted on cantilever) and catch (conically machined in housing), "flap-opening" SMA wire, return spring, "flapclosing" SMA wire, and pulley. To open the flaps, current is passed through the "flap-opening" SMA wire, which allows the wire to heat and contract, thereby pulling down on the left side of the cantilever. As a result of this force, the cantilever rotates counterclockwise, and rotates the flap connection, effectively opening the flap. When the cantilever has rotated fully, the detent locks into the catch, and holds the flap open, without the need for constant current. When closing of the flap is desired, current is then supplied to the "flap-closing" SMA wire, which contracts and exerts a force on the right side of the cantilever. This force is enough to pull the detent out of the catch and with the assistance of the return spring, pulls the cantilever clockwise and closes the vent flap. The detent and catch system serves as a failsafe mechanism; it was predicted that vibrational forces inservice would be enough to disengage the catch if the flaps did not close during actuation. Details of each component in the design are given below.

Two Flexinol® shape-memory alloy wires were used in the design with a diameter of $0.305 \mathrm{~mm}(0.012 \mathrm{in})$, total length of $292.1 \mathrm{~mm}$ (11.5 in) ("flap-opening" wire) and $134.6 \mathrm{~mm}$ (5.3 in) ("flap-closing" wire), and $90^{\circ} \mathrm{C}$ actuation temperature. A steel wire extension spring with a $25.4 \mathrm{~mm}$ (1 in) rest length, outer diameter $4.75 \mathrm{~mm}$ (0.187in), wire diameter $0.58 \mathrm{~mm}$ (0.023in) and a spring constant of $0.088 \mathrm{~N} / \mathrm{mm}(0.5 \mathrm{lbf} / \mathrm{in})$ was used as the bias spring. The pulley was $10.16 \mathrm{~mm}(0.4 \mathrm{in})$ thick, with a $12.7 \mathrm{~mm}(0.5 \mathrm{in})$ diameter and $3 \mathrm{D}$ printed from ABS. To insure that the "flap-opening" wire made good contact with the pulley, two grooves $(1.27 \mathrm{~mm}(0.05 \mathrm{in}))$ were printed at $2.03 \mathrm{~mm}$ (0.08in) from each end of the pulley. The cantilever was also 3D printed from ABS with a total length of $29.97 \mathrm{~mm}$ (1.18in). Features were printed into the cantilever so that each of the SMA wires could be looped over or through the cantilever to insure good contact during operation. The detent had a stainless steel body with a nylon ball with a $3.18 \mathrm{~mm}(0.125 \mathrm{in})$ diameter and nose force of 9-22N (2-5lbf), and was press fit into the cantilever. 
The catch was conically machined into the housing in line with the location of the detent when the vent flaps were in the fully open position. A $9 \mathrm{~V}$ power supply was used for testing and demonstration purposes.
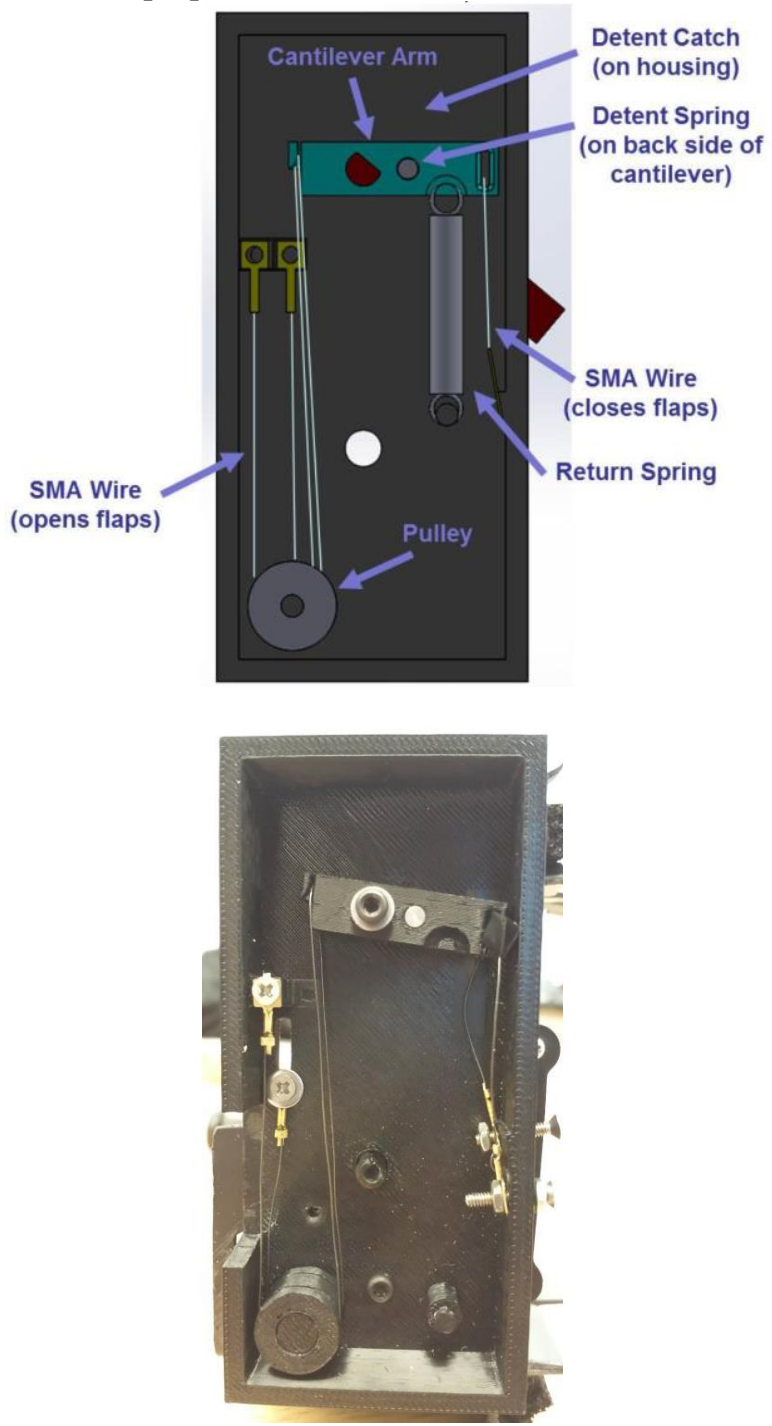

Figure 30: SolidWorks normal view of the proposed AHV design with the components indicated (top) and photograph of assembly prior to bias spring installation (bottom)

\subsubsection{Calculations and Use of Design Tools}

Several aspects of functionality were considered in selection of the appropriate Flexinol ${ }^{\circledR}$ wires for the AHV design including: output stress, actuation (i.e. strain), actuation temperature, and cooling time. Figure 31 shows a free body diagram (FBD) with accompanying balance equations to determine the output force required for the "flap-opening" SMA wire. The maximum allowable stress in each SMA wire (as indicated by Dynalloy) was $250 \mathrm{MPa}$, corresponding to a force of $36.48 \mathrm{~N}$. The maximum allowable force for the wire in addition to the minimum wire force of $23.35 \mathrm{~N}$ stated above were used to determine a viable return spring in the final design.

$$
\begin{gathered}
L_{w}=8.89+L_{v}=38.10-1 \\
M=F_{v} L_{v}+F_{r} L_{r}-F_{w} L_{w}>0 \\
F_{w}>\left(F_{v} L_{v}+F_{r} L_{r}\right) / L_{w}
\end{gathered}
$$

Figure 31: Free body diagram and force balance equations for determining minimum force required from SMA wire; the pivot point where $M$ is located is taken to be the origin. Note: all forces are in Newtons $(N)$, all lengths in millimeters $(\mathrm{mm})$

Spring scale measurements were taken on the disassembled production unit to determine the amount of force produced by the free hanging, fully opened, vent flaps. Figure 32 shows the force and length values for the assembly (measured), along with the return spring force $\left(F_{r}\right)$ (reported by manufacturer).

$$
\begin{array}{ll}
F_{v}:=1.33 \mathrm{~N} & F_{w}=16.369 \mathrm{~N} \\
\hline L_{v}:=38.1 \mathrm{~mm} & L_{w}:=8.89 \mathrm{~mm} \\
\hline F_{r}=34.385 \mathrm{~N} & \\
\hline
\end{array}
$$

Figure 32: Vent flap force $(F v)$, length of vent flaps $(L v)$, moment arm of the SMA wire $(L w)$, minimum value of $(F w)$, return spring force $(F r)$

As SMA wire force is a function of wire diameter, the force could be achieved through multiple wire length and diameter combinations. The most feasible option for this design was a $0.305 \mathrm{~mm}(0.012 \mathrm{in})$ Flexinol ${ }^{\circledR}$ wire that could exert a total of 25.177 $\mathrm{N}$ when doubled over.

To achieve full opening of the flaps (rotation angle of $\left.40^{\circ}\right)$, an SMA actuation distance of $6.45 \mathrm{~mm}(0.254$ in) was required. As stated by Dynalloy, actuation distance can vary from $2-5 \%$ of wire length depending on application; thus $3 \%$ actuation was used for calculations. The overall wire length for the "flap-opening" SMA wire was $292.1 \mathrm{~mm}$ (11.5 in), and half of it this length (146.05 mm (5.75 in)) contributes to actuation. Thus, a linear actuation distance of $4.38 \mathrm{~mm}(0.172 \mathrm{in})$ could be achieved, corresponding to $31.0^{\circ}$ of rotation. The "flap-closing" wire was $134.62 \mathrm{~mm}$ (5.3 in) and resulted in a calculated actuation of about $4.04 \mathrm{~mm}$ (0.159 in).

As previously mentioned, the austenitic starting transformation temperature (As) was desired to be increased from $90^{\circ} \mathrm{C}$ to $110^{\circ} \mathrm{C}$. Using $8 \mathrm{MPa} /{ }^{\circ} \mathrm{C}$, the stress in the wire needed to be $160 \mathrm{MPa}$ (corresponding to a force of $23.35 \mathrm{~N}$ ) in the closed vent position to achieve $110^{\circ} \mathrm{C}$ As. The calculated stress was below the maximum allowable stress for the wire, indicating that the applied stress would not shift the strain range of the wires. 


\subsubsection{Prototyping and Testing}

The SMA cooling time, and thus vent closing time, at room temperature in static air for the $0.305 \mathrm{~mm}$ diameter wire was $6.8 \mathrm{~s}$, well below the $15 \mathrm{~s}$ constraint. Though the final prototype did not achieve full opening of the vent flaps (an actuation angle of $30^{\circ}$ was achieved), the rest of this design met the criteria outlined in the Overview section. Most importantly, the final prototype eliminated the need for continuous current supply, via the detent and catch. The detent engaged in the catch most of the time, thus successfully holding the flaps open without the need for a constant current supply. However, minimal force (less than anticipated during driving) displaced the detent, suggesting that the flaps may close prematurely in practice (perhaps when loading or unloading the trunk in everyday use).

\subsubsection{Discussion and Review}

Both redesign concepts for the AHV met most of the design requirements. Each succeeded in increasing the actuation temperatures of the wires or springs by increasing the applied stresses. The CASMART design tool effectively predicted the maximum stresses experienced by the SMA spring used in the "opposed-pulley" design. Knowledge of the maximum stresses in turn helped inform the best SMA spring geometry to stay below the maximum allowable stress $(250 \mathrm{MPa})$. Consistent stroke lengths were achieved during cyclic testing and this behavior suggested that the SMA springs and wires stayed below the $250 \mathrm{MPa}$ stress, and further supported the design tool predictions.

\section{CONCLUSION}

This article describes CASMART's work to develop and compile a set of design tools and case studies based on the group's collaborative best practices. In an effort to promote the evaluation and comparison of actuation forms, the CASMART Design Working Group initiated a student design challenge in 2015. Six teams of graduate and undergraduate students from Colorado School of Mines, Texas A\&M University, and University of North Texas competed in the design challenge. The teams completed design challenges that highlight the development and use of design tools for tubes (rotary), wire (linear), helical coil (linear), and plate (bending). Five teams completed the challenge by demonstrating their hardware solutions at a special session at Smart Materials, Adaptive Structures, and Intelligent Systems Conference (SMASIS) 2015 in Colorado Springs, CO. Four case studies were presented: Reconfigurable SMA-Based solar array deployment mechanism using SMA torque tube, spring based Sunshade solar, passive gas turbine core airflow temperature controller, and a wire based Corvette active hatch redesign.

The CASMART 2015 Design Challenge provided some key feedback. The opportunity to participate in a challenge with industry and professional researcher mentoring was both engaging and valuable for the students. The ability to compare SMA element forms early in the design process is extremely difficult without comparable first order models that enable scoping studies. The design freedom enabled by considering a variety of SMA element forms led directly to the teams' creative solutions. Additional work is needed to make simple-to-use design tools available to the SMA designer. Future improvements to the design tools were identified, including the addition of friction, heat transfer, and operation rate under specified conditions. Finally, the challenge and value of building real hardware to validate your concept, modeling, and design cannot be underestimated.

\section{ACKNOWLEDGMENTS}

The authors would like to acknowledge CASMART's member institutions for their support of our consortium and the Boeing Company, Dynalloy, and Fort Wayne Metals for supplying materials.

\section{REFERENCES}

[1] Benafan, O., J. Brown, F. T. Calkins, P. Kumar, A. P. Stebner, T. L. Turner, R. Vaidyanathan, J. Webster, and M. L. Young. "Shape Memory Alloy Actuator Design: CASMART Collaborative Best Practices and Case Studies." International Journal of Mechanics and Materials in Design Int J Mech Mater Des 10.1 (2013): 1-42.

[2] Benafan, Othmane, Jeff Brown, F. Tad Calkins, Parikshith Kumar, Aaron Stebner, Travis Turner, Raj Vaidyanathan, John Webster, and Marcus L. Young. "Shape Memory Alloy Actuator Design: CASMART Collaborative Best Practices." ASME 2011 Conference on Smart Materials, Adaptive Structures and Intelligent Systems, Volume 1 (2011).

[3] Czarnocki, Isabel, Wonhee Kim, Brent Utter, Jonathan Luntz, Diann Brei, and Paul Alexander. "Design of SMA Helical Actuators: An Experimental Study." Volume 1: Development and Characterization of Multifunctional Materials; Modeling, Simulation and Control of Adaptive Systems; Integrated System Design and Implementation (2013).

[4] An, Sung-Min, Junghyun Ryu, Maenghyo Cho, and Kyu-Jin Cho. "Engineering Design Framework for a Shape Memory Alloy Coil Spring Actuator Using a Static Two-state Model." Smart Mater. Struct. Smart Materials and Structures 21.5 (2012): 055009.

[5] Stebner, A.P., and L.C. Brinson. "Explicit Finite Element Implementation of an Improved Three Dimensional Constitutive Model for Shape Memory Alloys." Computer Methods in Applied Mechanics and Engineering 257 (2013): 17-35.

[6] Saleeb, A.F., S.A. Padula, and A. Kumar. "A Multi-axial, Multimechanism Based Constitutive Model for the Comprehensive Representation of the Evolutionary Response of SMAs under General Thermomechanical Loading Conditions." International Journal of Plasticity 27.5 (2011): 655-87.

[7] Lagoudas, Dimitris C. 2008. Shape Memory Alloys, Modeling and Engineering Applications. Springer Verlag.

[8] Benafan, O., R. D. Noebe, S. A. Padula, and R. Vaidyanathan. "Microstructural Response During Isothermal and Isobaric Loading of a Precipitation-Strengthened Ni-29.7Ti-20Hf High-Temperature Shape Memory Alloy." Metall and Mat Trans A Metallurgical and Materials Transactions A 43.12 (2012): 4539-552.

[9] Wojcik, C.: Shape memory properties of nickel rich Ni-Ti alloys. In: Pelton, A., Hodgson, R., Duerig, T. (eds.) SMST 2003: International Conference on Shape Memory and Superelastic Technologies, pp. 4352 (2003)

[10] Lagoudas, D.C., Miller, D.A., Rong, L., Kumar, P.K.: Thermomechanical fatigue of shape memory alloys. Smart

Mater. Struct. 18(8), 085021 (2009) 
[11] Calhoun, C., R.W. Wheeler, T. Baxevanis, and D.C. Lagoudas. "Actuation Fatigue Life Prediction of Shape Memory Alloys under the Constant-stress Loading Condition." Scripta Materialia 95 (2015): 5861.

[12] Noebe, R., Draper, S., Gaydosh, D., Garg, A., Lerch, B., Penney, N., Bigelow, G., Padula, S., Brown, J.: Effect of thermomechanical processing on the microstructure, properties, and work behavior of a $\mathrm{Ti}(50.5) \mathrm{Ni}(29.5) \mathrm{Pt}(20)$ high-temperature shape memory alloy. In: SMST 2006: Proceedings of the International Conference on Shape Memory and Superelastic Technologies, 409-426 (2008)

[13] Calkins, F.T., Mabe, J.H.: Shape memory alloy based morphing chevrons: full scale static engine test. Paper No. AIAA-2007-3438. In: 13th AIAA/CEAS Aeroacoustics Conference, Rome, Italy (2007)

[14] Bigelow, G.S., Padula II, S.A., Garg, A., Gaydosh, D., Noebe, R.D.: Characterization of ternary NiTiPd high-temperature shapememory alloys under load-biased thermal cycling. Metall. Mater. Trans. A 41(12), 3065-3079 (2010)

[15] Padula II, S., Qiu, S., Gaydosh, D., Noebe, R., Bigelow, G., Garg, A., Vaidyanathan, R.: Effect of upper-cycle temperature on the loadbiased, strain-temperature response of

NiTi. Metall. Mater. Trans. 43A, 4610 (2012)

[16] Kim, Wonhee, Brian M. Barnes, Jonathan E. Luntz, and Diann E. Brei. "Conglomerate Stabilization Curve Design Method for Shape Memory Alloy Wire Actuators With Cyclic Shakedown." Journal of Mechanical Design J. Mech. Des. 133.11 (2011): 111010.

[17] A.M. Wahl, Mechanical Springs, McGraw-Hill, New York, 1963.

[18] E.J. Hearn, Mechanics of Materials - An Introduction to the Mechanics of Elastic and Plastic Deformation of Solids and Structural Materials (3rd Edition), Elsevier, 1997, p. 297-325.

[19] C.J. Ancker, J.N. Goodier, J. Appl. Mech. 25 (1958) 471-479.

[20] Piascik, Bob, et al. "Materials, structures, mechanical systems, and manufacturing roadmap." NASA TA (2012): 12-2.

[21] Leipold, M., et al. "Solar sail technology development and demonstration." Acta Astronautica 52.2 (2003): 317-326.

[22] Hartl, D. J., \& Lagoudas, D. C. (2007). Aerospace applications of shape memory alloys. Proceedings of the Institution of Mechanical Engineers, Part G: Journal of Aerospace Engineering, 221(4), 535-552. [23] Huang, Weimin. "Shape memory alloys and their application to actuators for deployable structures." (1998).

[24] Saunders, R. N., Hartl, D. J., Boyd, J. G., \& Lagoudas, D. C. "Modeling and development of a twisting wing using inductively heated shape memory alloy actuators." SPIE Smart Structures and Materials + Nondestructive Evaluation and Health Monitoring. International Society for Optics and Photonics, 2015.

[25] Wheeler, Robert W., Darren J. Hartl, Yves Chemisky, and Dimitris C. Lagoudas. "Modeling of Thermo-mechanical Fatigue and Damage in Shape Memory Alloy Axial Actuators." Behavior and Mechanics of Multifunctional Materials and Composites 2015 (2015).

[26] "Deployment Mechanisms and Structures." GOES DataBook. GSFC. Web. 